\title{
EL JUICIO CONSTITUCIONAL DE PROPORCIONALIDAD DE LAS LEYES PENALES: ¿LA LEGITIMACIÓN DEMOCRÁTICA COMO MEDIO PARA MITIGAR SU INHERENTE IRRACIONALIDAD?*
}

\author{
José ÁNGEL FERNÁNDEZ CRUZ
}

RESUMEN: El juicio constitucional de proporcionalidad constituye el criterio estructural para la concreción de los derechos fundamentales que puede otorgar una mayor protección constitucional a los principios y límites al Ius puniendi. El Tribunal Constitucional tiene como cometido establecer qué principios y límites penales se pueden incorporar a las disposiciones o normas de derecho fundamental y, de esta manera, configurar un sistema de precedentes en el control constitucional de las leyes penales. No obstante, la inherente irracionalidad que contienen cualquier test de constitucionalidad y, por tanto, también el de proporcionalidad, puede mitigarse a través de la incorporación de algunas reglas o reformas fundamentadas en la legitimación democrática y, en especial, la discursiva.

PALABRAS CLAVE: Proporcionalidad penal - Tribunal Constitucional racionalidad discursiva.

\section{THE CONSTITUTIONAL JUDGMENT OF PROPORTIONALITY OF THE CRIMINAL LAWS: DEMOCRATIC LEgITIMATION AS A MEANS TO MITIGATE ITS INHERENT IRRATIONALITY?}

ABSTRACT: The constitutional judgment of proportionality represents the fundamental criteria for the fulfillment of the basic rights that may grant a higher constitutional protection to the principles and limitations to the Ius puniendi. The Constitutional Court's purpose is to

\footnotetext{
La presente investigación forma parte del proyecto de investigación FONDECYT No 1085075 denominado Racionalidad de las leyes penales y Estado Constitucional.

** Doctor en Derecho Penal, profesor de Derecho Penal de la Facultad de Ciencias Jurídicas y Sociales, Universidad Austral (CHILE). Correo electrónico: josefernandez@uach.cl

Fecha de recepción: 3 de mayo de 2010.

Fecha de aprobación: 15 de julio de 2010.
} 
set what principles and criminal limitations may be incorporated to the provisions or norms of fundamental right and, as such, to configure a system of precedents in the constitutional control of the criminal laws. Nevertheless, the inherent irrationality that any constitutionality test may contain and, thus, of proportionality too, can be mitigated through the incorporation of some regulations or reforms based on the democratic legitimation, especially, the discourse rationality.

KEY WORDS: Criminal Proportionality - Constitutional Court Discourse rationality.

\section{INTRODUCCIÓN: PRECISIONES TERMINOLÓGICAS}

El examen decisivo en el control constitucional de las leyes penales es el denominado principio de proporcionalidad en sentido amplio. Este examen se compone de tres elementos: la aptitud o idoneidad de la medida para alcanzar la finalidad propuesta; la necesidad de la medida, la cual depende de la ausencia de una medida menos gravosa; y la razonabilidad de la medida, también denominada como proporcionalidad en sentido estricto o ponderación. Esta concepción amplia del principio de proporcionalidad -difundida por la jurisprudencia constitucional alemana y española- intenta superar la clásica noción estricta, referida tan solo a la exigencia de adecuación entre la gravedad de la pena y del delito a través de la incorporación de juicios fácticos o empíricos sobre los costes y beneficios de la medida ${ }^{1}$.

$\mathrm{Su}$ fundamento histórico se encuentra en el surgimiento del Estado moderno y, en especial, en el contractualismo iusnaturalista de la Ilustración ${ }^{2}$. La supeditación de los ciudadanos a las restricciones impuestas por el Estado se fundamenta en la obtención de unas mayores cotas de

1 Existen dentro de la dogmática penal, sin embargo, otras posturas dentro de una concepción más amplia del principio de proporcionalidad, pero todas incluyen, en mayor o menor medida, el principio o juicio de necesidad de la injerencia penal. Véase, Gómez Benítez, José Manuel (2001). "La idea moderna de la proporcionalidad de las penas", Estudios Penales, p. 55; Sánchez García de PAZ, Isabel (1994). "El principio constitucional de proporcionalidad en el derecho penal”, La Ley, 1994, T. IV, p. 1117.

2 No obstante, podemos encontrar alusiones en periodos históricos anteriores. Aristóteles expresaba que el talión constituye una fuerza de cohesión en las relaciones cotidianas de los hombres, pero "siempre que se la entienda en términos de proporcionalidad y no de igualdad mecánica”. Aristóteles. Obras completas. Ética a Nicómano. Disponible en http:// www.uruguaypiensa.org.uy/imgnoticias/650.pdf [Fecha de visita 11 de febrero de 2010), p. 139. No obstante, estos precedentes históricos no tenían el contenido político que le otorgó la filosofía política de la Ilustración. Sobre la evolución histórica del principio de proporcionalidad véase Bernal Pulido, Carlos (2005). El principio de proporcionalidad y derechos fundamentales, Madrid: Centro de Estudios Constitucionales, pp. 40-52. 
libertad y seguridad y, por tanto, demanda que las injerencias del Estado se realicen solo en casos necesarios y con la magnitud imprescindible. Podríamos convenir que la superación del derecho penal del Antiguo Régimen se realizó a través del principio de legalidad y proporcionalidad ${ }^{3}$. Su primera formulación en el Estado moderno debemos encontrarla en el derecho penal de la Ilustración con la instauración de las penas abstractas y su cuantificación temporal y pecuniaria, situación que permitió una imposición mesurada de estas ${ }^{4}$.

A la conocida formulación de Becaria se añade el desarrollo notable en el derecho de policía prusiano que formuló, por primera vez, el principio de proporcionalidad en sentido amplio5. Posteriormente, el principio de proporcionalidad en sentido amplio ha adquirido expresa o implícitamente rango constitucional a través de la doctrina y jurisprudencia constitucional alemana y española ${ }^{6}$. La incorporación del principio de proporcionalidad a todas las expresiones del Estado de Derecho que pueden limitar los derechos fundamentales y su aplicación como control constitucional del legislador democrático y del aplicador judicial han supuesto su culminación como principio limitador del poder estatal ${ }^{7}$. Incluso, el principal artífice del auge del principio de proporcionalidad en el Derecho chileno ha sido el propio Tribunal Constitucional ${ }^{8}$, aunque de una manera todavía dubitativa e imprecisa?.

La incorporación del principio de proporcionalidad como parámetro de control de constitucionalidad de las leyes penales (sustantivas) ha sido tardía, situación que resulta extraña si tenemos presente su inherente capacidad para limitar los derechos fundamentales. Así, se produce una curiosa evolución histórica de las relaciones del principio de proporcionalidad en el derecho penal: la idea de proporcionalidad tuvo su origen, al menos teóricamente, en las relaciones entre el delito y la pena y, posteriormente, tras una nueva formulación en el ámbito del derecho admi-

3 Gómez Recio, Fernando (2000). "El principio de proporcionalidad penal, doctrina constitucional y su aplicación a los delitos de tráfico de drogas", Actualidad Penal, No 45, p. 950.

4 Ferrajoli, Luigi (1995). Teoría del garantismo penal, Derecho y razón, Madrid: Trotta, p. 398. De esta manera el art. 8 de la Declaración de los Derechos del Hombre y el Ciudadano declara: "La ley no debe establecer otras penas que las estricta y evidentemente necesarias".

5 En el derecho administrativo suele citarse el Tratado de Von Berg de 1790 como la primera obra donde se enuncia el principio de proporcionalidad en sentido amplio, pero es a partir de la obra de Otto Mayer cuando adquiere la importancia como límite al derecho sancionador. Mayer, Otto (1940). Derecho administrativo alemán, Buenos Aires: De Palma, p. 31.

6 Sánchez García de Paz (1994) 1114.

7 Sánchez García de PAZ (1994) 1118.

8 Destacamos las sentencias del Tribunal Constitucional de 7 julio de 2007, Rol N 786 y de 6 de marzo de 2008, Rol N 825.

9 Esta situación se ha dado también en otros sistemas jurídicos como el español. Por todos, De la Mata Barranco, Norberto J. (2007). El principio de proporcionalidad penal, Valencia: Tirant lo Blanch, p. 78. 
nistrativo sancionador y su incorporación por parte de algunos tribunales constitucionales ha regresado al derecho penal como límite a los límites de los derechos fundamentales ${ }^{10}$.

El término "principio de proporcionalidad" puede ser entendido de distintas maneras. Aquí destacaremos tres de ellas, especialmente las relacionadas con el control constitucional de las leyes penales: como principio constitucional, como método de interpretación y como control o test de constitucionalidad.

La proporcionalidad como principio constitucional supone una obligación general de ponderar, de sopesar las intervenciones estatales en los derechos fundamentales que se manifiestan en la fase de creación normativa, en la de aplicación de estas y, en el tema que nos ocupa, en el control de constitucionalidad. La exigencia de mesura en las intervenciones del Estado se encuentra unida a la idea de justicia material ${ }^{11}$ y en el mismo fundamento del Estado de Derecho. La noción de proporcionalidad pertenece a la deontología del derecho, impone un determinado criterio de justificación del mismo ${ }^{12}$.

Esta primera acepción posee ciertas características como son la fundamentalidad, la generalidad y una cierta vaguedad. En cuanto a la fundamentalidad varios son los sentidos: en sentido lógico (normas de las que se derivan otras); teleológico (normas que señalan los fines o propósitos del ordenamiento); competencial (normas que atribuyen funciones a otras); jerárquica (normas que el sistema de fuentes del derecho otorgan una supremacía sobre otras, donde también se pueden incluir las normas competenciales); y axiológico (normas que expresan criterios éticos o políticos que resultan básicos para el sistema de convivencia o de creencias) ${ }^{13}$.

En cuanto a la fundamentación del principio de proporcionalidad dentro de un concreto sistema jurídico-constitucional, debemos señalar que, si bien una doctrina cada vez más mayoritaria se muestra de acuerdo en reconocer rango constitucional al principio de proporcionalidad,

10 Si bien podemos encontrar puntos de conexión con la clásica concepción penal, especialmente, con el subprincipio de necesidad. Así, parte de la doctrina entiende que la formulación de Beccaria comprende no solo un juicio interno (retribución), sino también de eficacia y utilidad de la pena como fundamento del principio de proporcionalidad. Asua Batarrita, Adela (1990). "Reivindicación o superación del programa de Beccaria", en ella misma: El pensamiento penal de Beccaria: su actualidad, Bilbao: Universidad de Deusto, pp. 21 y 26.

11 BARnes VÁsquez, Javier (1998). "Principio de proporcionalidad en el derecho comparado y comunitario", Cuadernos de Derecho Público, No 5, p. 23.

12 Lascuraín SÁnchez, Juan Antonio (1998). "El principio de proporcionalidad penal”, Cuadernos de Derecho Público, No 5, p. 159.

13 Prieto Sanchís, Luis (1997). "La doctrina de los principios generales del Derecho y la distinción entre principios y reglas”, en él mismo: Lecciones de teoría del Derecho, Madrid: McGraw-Hill, p. 341. 
discrepa acerca del o los preceptos constitucionales donde puede considerarse consagrado ${ }^{14}$. Esta discusión tiene como principal causa el hecho de que el principio constitucional de proporcionalidad, al igual que nuestra CPR, no se encuentra sancionado expresamente en gran parte de los textos constitucionales ${ }^{15}$. No obstante, su consagración podemos extrapolarla de los principios reconocidos en las constituciones modernas, y gran parte también en nuestra Carta ${ }^{16}$. En todo caso, parece existir un cierto consenso en considerar que la libertad -como uno de los valores superiores del Estado de Derecho- reclama la prohibición de exceso respecto de las injerencias o intervenciones estatales y, por ende, de un juicio de proporcionalidad ${ }^{17}$. Especial importancia posee la vinculación del principio de proporcionalidad con el derecho a la libertad, puesto que las injerencias penales consisten, fundamentalmente, en privaciones o restricciones de libertad. Aquí, la doble relación. Por una parte, el injusto típico supone - a través de la amenaza de la pena- un límite al principio de maximización de la libertad de los ciudadanos; y por otra, la concreta imposición de la pena supone el menoscabo más intenso de esta ${ }^{18}$.

14 Aguado Correa, Teresa (1999). El principio de proporcionalidad en derecho penal, Madrid: Edersa, pp. 120 y ss.

15 En especial, la Constitución española y la Ley Fundamental alemana. No obstante, tanto la Carta de Derechos Fundamentales de la Unión Europea (art. 52.1) como la malograda Constitución Europea (art. II.109.3 y 112.1) recogen expresamente el principio de proporcionalidad.

16 Existe una corriente doctrinal -específicamente en el ámbito penal- la cual entiende que cualquier injerencia estatal en los derechos fundamentales de la persona se encuentra estrechamente ligada a su dignidad que, en último término, supone una proporcionalidad de la medida. El problema que plantea esta posición radica en la dificultad de definir este valor o principio sin referencia a otros valores, derecho o libertades también reconocidos constitucionalmente. De la Mata Barranco (2007) 75. Como manifestación del derecho a la dignidad de la persona, parte de la doctrina ha deducido el principio de proporcionalidad de la prohibición de tratos inhumanos y degradantes. ToRío López, Ángel (1986). "La prohibición constitucional de penas y tratos inhumanos o degradantes", Poder Judicial, No 4, pp. 69-82. Parte de la jurisprudencia del TC español y de la doctrina, entiende que no se puede afirmar una completa identidad entre estos dos principios. Sin duda, una pena degradante podrá entenderse desproporcionada, pero en el caso contrario de que una pena respetuosa con el principio de humanidad de las penas no conlleva necesariamente una proporcionalidad adecuada. Entre otras, SsTC 65/1986 y 150/1991; JAÉN VALLEJO, Manuel (1999). Los principios superiores del Derecho Penal, Madrid: Dykinson, p. 43. Respecto del principio de igualdad, si bien se encuentra estrechamente relacionado con el principio de proporcionalidad, no estamos ante principios idénticos. Así, todo lo que atente contra el principio de igualdad será desproporcionado, aunque no tiene por qué ocurrir a la inversa, en particular, si a todos o a la gran mayoría se trata de forma desproporcionada. Por último, desde la concepción del principio de proporcionalidad en sentido estricto y, en especial, desde la perspectiva penal, desde Becaria o Lardizábal, se reconoce en la doctrina penal que este principio evoca la idea de justicia inmanente a todo Derecho.

17 Entre otros, Aguado Correa (1999) 49; De la Mata Barranco (2007) 72.

18 Así, el TC español declara que el principio de proporcionalidad debe establecer qué principios, derechos o valores constitucionales son afectados por una injerencia estatal, y en el contexto sancionador nos remite al ámbito de la libertad personal. STC 136/1999. 
Pero quizá el precepto constitucional más cercano al principio de proporcionalidad, que incluso podemos considerar como su concreta consagración en nuestra Norma Fundamental, se encuentra en la prohibición de diferencias arbitrarias contenida en el inc. $2^{\circ}$ del art. 19 de la $\mathrm{CPR}^{19}$. La arbitrariedad del poder político se puede manifestar de dos formas: cuando se prevén o adoptan sanciones cuya gravedad no está en consonancia con la gravedad de lo que las motiva en un análisis comparativo con otras sanciones; pero también cabe afirmar que estamos ante una medida arbitraria cuando en sí misma -sin necesidad de realizar un juicio comparativo- se limitan los derechos fundamentales ${ }^{20}$. La primera concepción se asemeja al contenido del principio de proporcionalidad en sentido amplio (idoneidad, necesidad y ponderación); y el segundo, a la legitimidad constitucional de la medida o injerencia que en el principio de proporcionalidad constituye un presupuesto previo.

En todo caso, la discusión sobre la fundamentación del principio de proporcionalidad, más que mostrar una discrepancia doctrinal, refuerza la idea de que estamos ante un límite al poder del Estado inherente a las constituciones liberales.

La segunda acepción del principio de proporcionalidad como método de interpretación diferencia las normas jurídicas entre principios y reglas. Estas últimas operan de manera "todo o nada", en el sentido que establece una solución concreta para el caso que prevé la norma. En cambio, los principios poseen un carácter abierto que significa que en algunos casos pueden ser tenidos en cuenta y en otros no ${ }^{21}$, o en otros ordenan una satisfacción en la mayor medida posible dentro de las posibilidades fácticas y jurídicas ${ }^{22}$. Por tanto, es también entendido como una regla de interpretación. El criterio de especialidad, superados los criterios de jerarquía normativa y cronológico, en ocasiones no resulta suficiente para resolver ciertas antinomias, concretamente, aquellas donde no es posible establecer una relación de especialidad entre dos normas. El modo de resolver estos conflictos entre principios (válidos, pero en permanente

19 En el mismo sentido, la STC de 6 marzo de 2008, Rol 825 en su Considerando Decimoctavo manifiesta: "Que la existencia de un trato diferente para una determinada categoría de delitos no es suficiente para concluir que ello es contrario a la Carta Fundamental, pues ésta no prohíbe establecer diferencias, sino que hacerlo arbitrariamente, esto es, careciendo de fundamento que pueda justificarlas”. En la doctrina, Nogueira AlCalá, Humberto (2010). "El principio de proporcionalidad y su aplicación en Sudamérica por la jurisdicción constitucional, con especial mención al tribunal constitucional chileno", en Carbonell, Miguel (coord.): El principio de proporcionalidad en la interpretación jurídica, Santiago: Librotecnia, pp. 400 y ss.

20 De la Mata Barranco (2007) 75. Así, en este último sentido apuntado encontramos en la jurisprudencia del TC español las Sentencias 129/1987 y 70/1988.

21 Dworkin, Ronald (1984). Los derechos en serio, Barcelona: Ariel, pp. 72-80.

22 Alexy, Robert (2007). Teoría de los derechos fundamentales, 2a ed., trad. de Bernal Pulido, Madrid: Centro de Estudios Constitucionales, p. 133. 
conflicto) recibe el nombre de "ponderación, razonabilidad o proporcionalidad".

Una regla para resolver conflictos entre principios del mismo valor o jerarquía, en palabras de Alexy, puede formularse de la siguiente manera: "cuando mayor sea el grado de no satisfacción o de afección de un principio, tanto mayor tiene que ser la importancia de otro" 23 . La diferencia con reglas puede formularse según Prieto Sanchís de la siguiente manera: "cuando dos reglas entran en conflicto interno, ello significa que, o bien, una de ellas no es válida, o bien, que una opera como excepción de la otra. En cambio, cuando la contradicción se entabla entre dos principios, ambos siguen siendo simultáneamente válidos, por más que en el caso concreto y de modo circunstancial triunfe uno sobre el otro. No son aplicables los criterios de especialidad, jerarquía o cronológico, ya que con frecuencia sucede que en un mismo caso resulta subsumible en dos derechos o principios tendencialmente contradictorios, como ocurre con la libertad de expresión y el derecho al honor, o la libertad y la seguridad colectiva" 24 .

La ponderación presupone el tercer de los modelos básicos de razonamiento jurídico, entendido como el razonamiento consistente en pasar de los principios a las reglas. En este tipo de razonamiento pueden distinguirse varias etapas. La primera consiste en verificar que ante una determinada situación existen principios o valores que pugnan en direcciones opuestas y que necesita algún tipo de ajuste: es decir, todos ellos no pueden satisfacerse al mismo tiempo, o no del todo. En la segunda etapa se establece una prioridad de un principio o valor sobre otro, dadas ciertas circunstancias, aduciendo las razones para ello. Finalmente, se construye una regla que supone la traducción en términos deónticos de esa prioridad.

El juicio de ponderación no debe ser visto como un sistema interpretativo alternativo a la subsunción, sino que, a juicio de parte de la doctrina de la Teoría del derecho, este opera en fases distintas. Cuando existe una colisión entre principios el paso previo al juicio de proporcionalidad consiste en subsumir tanto la finalidad perseguida por la norma como la injerencia que esta comporta en el campo de aplicación de dos prin$\operatorname{cipios}^{25}$. Así, por ejemplo, para afirmar que una pena resulta desproporcionada por representar un límite injustificado al ejercicio de un derecho, antes resulta preciso que el caso enjuiciado pueda ser subsumido no una, sino dos veces: en nuestro caso, en el derecho fundamental que pretende proteger el delito y el derecho fundamental que pretende limitar. Poste-

\footnotetext{
23 Alexy (2007) 161.

24 Prieto SAnchís, Luis (2003). Justicia constitucional y derechos fundamentales, Madrid: Trotta, pp. 126-127.

25 Prieto Sanchís (2003) 193.
} 
riormente, superada la antinomia prima facie entre principios a través del principio de proporcionalidad se produce una regla que funciona como premisa previa normativa y que se aplicará a través de un proceso de subsunción y de una coherente aplicación del precedente a casos futuros semejantes ${ }^{26}$.

Por último, el principio de proporcionalidad es entendido como un test de constitucionalidad de las leyes. En este caso, estamos ante la aplicación concreta al campo del derecho constitucional del principio de proporcionalidad entendido tanto como una obligación de ponderar, como una regla de interpretación. La ponderación constituye un modelo de razonamiento especialmente apto en el ámbito del derecho constitucional. Cuando fracasan las reglas tradicionales de resolución de antinomias y cuando tampoco se quiere abdicar de la toma de consideración de los preceptos constitucionales en toda clase de conflictos, la ponderación parece ser el procedimiento más racional (o razonable) para justificar unas decisiones adoptadas frecuentemente con escaso respaldo normativo ${ }^{27}$. El denominado principio de proporcionalidad, a grandes rasgos, constituye un test o juicio de solución de conflictos entre derechos constitucionales o, si se quiere, entre verdaderos principios de rango constitucional $^{28}$.

El juicio constitucional de proporcionalidad entendido como prohibición de exceso o como método de interpretación para superar un conflicto entre principios, no viene determinado a priori su concreta forma y contenido ${ }^{29}$ y tampoco debe resultar idéntico para todos los poderes e instituciones. Por esta razón, el denominado principio de proporcionalidad en sentido amplio adoptado por los tribunales constitucionales comparados y avalado por gran parte de la doctrina, es una manera, no la única, de realizar este test obligatorio de constitucionalidad ${ }^{30}$.

La jurisprudencia y la doctrina suelen acudir a un variado elenco de términos para referirse al principio de proporcionalidad en el ámbito de la interpretación y aplicación de los derechos fundamentales. La jurisprudencia constitucional española lo ha designado como "criterio", "factor", "regla" o "juicio" de proporcionalidad, así como, "canon de constitucionalidad" 31 . En el presente estudio, teniendo en cuenta las anteriores consideraciones, utilizaremos el término de "juicio" o "test constitucional de proporcionalidad", en reemplazo del confuso término

Prieto SANChís (2003) 194.

Prieto SANChís (2003) 18.

STC 215/1994, voto particular de Gimeno Sendra.

De la Mata Barranco (2007) 44.

Véase, por ejemplo, los tests de proporcionalidad utilizados por la Corte Suprema estadounidense que se ven más adelante.

Bernal Pulido (2005) 221. 
"principio de proporcionalidad en sentido amplio", sin perjuicio de que la mayoría de la doctrina lo utiliza y que, en ciertos casos, nos veamos obligados a emplear esta expresión a la hora de citarla.

La segunda precisión que debemos realizar sobre el principio de proporcionalidad estriba en afirmar que su principal ámbito de aplicación no radica en el control de constitucionalidad de las leyes, sino en el propio proceso de creación normativa. El principio de proporcionalidad debería constituir uno de los principales criterios para concretar el contenido de los derechos fundamentales en sede legislativa. Pero, como afirma Silva Sánchez, se viene produciendo un retroceso del Poder Ejecutivo y Legislativo en su cumpliendo, en contraposición, de la praxis judicial, donde se percibe un creciente esfuerzo por incorporar este principio penal dentro, claro está, de los parámetros del principio de legalidad ${ }^{32}$, situación que se puede extrapolar a la jurisprudencia constitucional. Son los poderes ejecutivo y legislativo los que poseen la capacidad para llevar a cabo los juicios de idoneidad y necesidad que, como veremos a continuación, se fundamentan en consideraciones empíricas.

En todo caso, una incorporación del principio de proporcionalidad, no solo por parte del TC, sino también por los órganos jurisdiccionales penales, es decir, un mismo discurso jurídico, constituiría un llamamiento al desarrollo de una buena técnica legislativa y a la reconsideración de sus decisiones en no pocas ocasiones desproporcionadas. No obstante, si bien la proporcionalidad en la injerencia de los derechos fundamentales debería estar presente en los debates parlamentarios y en las consideraciones del Poder Ejecutivo, de esta circunstancia no puede derivarse la conclusión de que estas instancias políticas están estructuradas por el principio de proporcionalidad ${ }^{33}$. Efectivamente, como trataremos al final de este estudio, las instancias políticas legitiman sus decisiones, no solo con argumentos éticos y sociales (empíricas), sino también en consideraciones democráticas y, especialmente, discursivas.

\section{1) CRÍTICA AL JUICIO CONSTITUCIONAL DE PROPORCIONALIDAD: LA TEORÍA DEL CONTENIDO ESENCIAL}

El juicio de proporcionalidad como medio de racionalización del derecho en sede constitucional viene siendo objeto de una intensa crítica. Dos son las principales objeciones generales: su carácter irracional y la ilegitimidad del TC para esgrimirlo como parámetro de constitucionalidad

\footnotetext{
32 Silva SÁnchez, Jesús María (1997). "Nuevas tendencias político criminales y actividad jurisprudencial del Tribunal Supremo”, en Romeo Casabona, Carlos (ed.): Dogmática penal, Politica criminal y criminología en evolución, Tenerife: Universidad de Tenerife, Centro de Estudios Criminológicos, p. 318.

33 En este sentido, Bernal Pulido (2005) 537.
} 
de las leyes. También, plantea problemas con su compatibilidad con otros tests de constitucionalidad, como el caso de la doctrina del contenido esencial.

La alta imprecisión a la que se ve condenado el juicio constitucional de proporcionalidad hace que este posea un alto componente valorativo llevado a cabo sobre una endeble base empírica y, por lo mismo, susceptible a un alto margen de error. Su aplicación resulta ineludiblemente subjetiva. Este juicio de constitucionalidad, según sus críticos, no constituye más que un argumento formal y ausente de contenido; un tópico ininteligible que gracias a su fuerza persuasiva ostenta una especial capacidad para enmascarar valoraciones subjetivas e irracionales ${ }^{34}$.

También, se ha manifestado que su extremada subjetividad se deriva de la pretensión de establecer una jurisprudencia constitucional ad hoc; afán de magnificar la justicia del caso concreto que conlleva un sacrificio desmedido para la coherencia, seguridad jurídica ${ }^{35}$ e igualdad. En efecto, la creciente presencia del test de proporcionalidad está motivada por su especial aptitud para lograr la justicia del caso concreto. Este hecho no resulta tan criticable, al menos, en nuestro actual sistema de recursos constitucionales. Si tras la aplicación del juicio de proporcionalidad a través del recurso de inaplicabilidad se considerara inconstitucional una determinada injerencia penal en varios casos concretos, existirán poderosos argumentos para expulsarla definitivamente del sistema jurídico conforme con el inc. $7^{\circ}$ del art. $93 \mathrm{CPR}$. Es decir, no estaríamos ante un sacrificio desmedido de la coherencia y la seguridad jurídica.

Tampoco el juicio constitucional de proporcionalidad asegura que la decisión finalmente adoptada sea la única decisión correcta, hecho que afecta a la propia legitimidad de este test de constitucionalidad. En cuanto a la pretensión de que el control de constitucionalidad de las leyes deba llegar a la única solución correcta, Alexy pone de manifiesto que ningún test de constitucionalidad, incluido el de proporcionalidad, puede desligarse de valoraciones que no son controlables por el propio juicio de constitucionalidad aplicado ${ }^{36}$.

Pero quizá la principal crítica radica en la legitimidad del TC para aplicar esta forma de controlar la constitucionalidad de las leyes. El juicio constitucional de proporcionalidad ha sido tildado como una especie de "composición salomónica", juicio que corresponde con exclusividad a los órganos políticos y, por ende, el TC carecería de legitimidad para llevarlo

\footnotetext{
34 Calvo González, José (1994). "Razonabilidad como relato (Narrativismo en la observancia y divergencia del precedente)", Revista del Poder Judicial, No 33, pp. 33-43.

35 Zagrebelsky, Gustavo (1996). El derecho dúctil: ley, derecho y justicia, Madrid: Trotta, en especial, Capítulos Sexto y Séptimo.

36 Alexy (2007) 173.
} 
a efecto ${ }^{37}$. Incluso, el extenso control de los tribunales constitucionales mediante la interpretación extensiva de las normas fundamentales (normas adscritas) conlleva el peligro para un sector de la doctrina de un cambio del modelo de Estado; del Estado democrático al Estado de la jurisdicción constitucional. Esto supondría trasladar el centro de gravedad de las controversias políticas a una institución legitimada exclusivamente para llevar a cabo discusiones jurídicas ${ }^{38}$.

El rendimiento del juicio constitucional de proporcionalidad queda limitado por la libertad del legislador para elegir los fines de la norma (racionalidad instrumental) y para adecuar la intervención al fin perseguido (racionalidad valorativa) en el seno del proceso de formación de la voluntad política. Como manifiesta, Sternberg-Lieben desde la óptica constitucional, el Parlamento se fundamenta en las mayorías y no en el conocimiento de los expertos. Es decir, las relaciones discursivas cumplen una función esencial en la elaboración de las leyes (penales) y, en principio, ausentes del control constitucional, salvo de los denominados presupuestos comunicativos constitucionalizados. La restringida posibilidad de fiscalización por parte del TC se debe a la intrínseca incertidumbre a la hora de la toma de decisiones legislativas. Debemos tener presente que las decisiones legislativas son fruto, en gran parte, de un proceso político y no de un proceso de descubrimiento ${ }^{39}$, fundamentadas, en nuestro caso, en las Ciencias empíricas y sociales.

Ahora bien, la crítica sobre la falta de legitimidad de los tribunales constitucionales para realizar el juicio constitucional de proporcionalidad tiene parte de su fundamento en los problemas de legitimidad de la propia jurisdicción constitucional en el seno del Estado social y democrático de derecho, es decir, en la tensión inherente entre el principio democrático y el principio de protección de los derechos fundamentales. Esta tensión debe tener presente la falsedad de un concepto ideal de democracia, donde todas las injerencias a los derechos fundamentales realizados por el legislador cuentan con el consentimiento real de todos sus titulares ${ }^{40}$. Esta tensión, según los partidarios del principio de proporcionalidad, solo puede mitigarse a través de la argumentación: cuando más racional sea un criterio o método para interpretar la Constitución, mayor será la legitimidad de la jurisdicción constitucional.

\footnotetext{
37 Jiménez Campos, Javier. (1999). Derechos fundamentales. Concepto y garantías, Madrid: Trotta, p.65.

38 Sternenberg-Liben, Detlev (2007). "Bien jurídico, proporcionalidad y libertad del legislador penal”, trad. de Ortiz de Urbina, en Hefendehl, Roland (ed.): La teoría del bien juridico. ¿Fundamento de legitimación del derecho penal o juego de abalorios dogmático?, Madrid: Marcial Pons, 2007, p. 122.

39 Sternenberg-Liben (2007) 120.

40 Por todos, Bernal Pulido (2005) 204.
} 
A pesar de las anteriores consideraciones, la práctica totalidad de la doctrina partidaria del test de proporcionalidad excluye una dimensión fuerte, cercana al juicio político-criminal subjetivo que evalúa la norma desde una perspectiva axiológica y funcional óptima. Distinto es el juicio constitucional de proporcionalidad, entendido como una garantía mínima del ciudadano frente al poder del Estado.

Otra crítica importante es la inclusión de los juicios de necesidad e idoneidad. Consideraciones fácticas sobre la idoneidad y necesidad de una determinada medida penal son esenciales en juicio legislativo de proporcionalidad, pero resultan improcedentes o, al menos, no estrictamente necesarias en el juicio constitucional de proporcionalidad. La inclusión de valoraciones externas termina en la conciliación de intereses sociales y políticos, función que corresponde al Poder Legislativo.

No obstante, parte de la doctrina entiende que si la función del principio de proporcionalidad es la de imponer un cierto contenido material al derecho penal -una razonable protección de libertad-su contenido se revela insuficiente si se limita a la denominada "proporcionalidad en sentido estricto: un balance entre los costes y los beneficios de libertad que la norma comporta. Resulta necesario incluir una comparación con otras medidas alternativas y sopesar si una de menor intensidad coactiva puede alcanzar similares objetivos de los que propone la norma objetada ${ }^{41}$.

Otro cuestionamiento radica en su condición de "arma de doble filo" que puede ser utilizada tanto para limitar como justificar el poder punitivo. Esta condición es compartida con la teoría del bien jurídico que, como veremos con posterioridad, comparte gran parte de su contenido y requisitos ${ }^{42}$.

Como conclusión a las críticas generales y de fondo, el juicio constitucional de proporcionalidad supone una actividad dejada a la subjetividad y discrecionalidad del intérprete que conlleva, inevitablemente, a una relativización de los derechos fundamentales ${ }^{43}$. Ahora bien, esta crítica puede tomar una dirección totalmente opuesta en el ámbito del control constitucional de la ley penal. Teniendo presente el escaso control en esta materia y la especial referencia de los tribunales respecto del legislador penal que, en no pocas ocasiones, toma tildes de sumisión, el juicio de

41 Lopera Mesa, Gloria P. (2006). Principio de proporcionalidad y ley penal, Madrid: Centro de Estudios Políticos y Constitucionales, p. 252.

42 Véase, una evolución histórica de la teoría del bien jurídico como límite y legitimación del Ius puniendi, Hormazábal, Hernán (1991). Bien juridico y Estado Social y Democrático de Derecho, Barcelona: P.P.U.

43 De Otto y Pardo, Ignacio (1983). "La regulación del ejercicio de los derechos y libertades. La garantía de su contenido esencial en el artículo 53.1 de la Constitución”, en MartínRetortillo / De Otto y Pardo (Coords.): Derechos fundamentales y Constitución, Madrid: Cuadernos Civitas de Derecho Constitucional, pp.115 a 119. 
proporcionalidad -al incluir nuevas argumentaciones jurídicas y fácticaspermite fundamentar un cambio jurisprudencial en el control constitucional de las leyes penales. Como manifiesta Bernal Pulido, "el sistema de derechos fundamentales que permanece abierto al cambio, puede adaptarse con facilidad a la aparición de nuevas razones que modifiquen su contenido normativo de tales derechos, que en todo caso queda garantizado siempre por las exigencias del principio de proporcionalidad" 44 .

\section{1) JUICIO CONSTITUCIONAL DE PROPORCIONALIDAD Y TEORÍA DEL CONTENIDO ESENCIAL}

El juicio constitucional de proporcionalidad plantea un problema de compatibilidad con la exigencia de respetar el contenido esencial de los derechos fundamentales ${ }^{45}$, situación que se agrava en nuestro caso que, al igual que en la Constitución española como alemana, se encuentra expresamente tipificado en nuestra CPR (art.19.26a). La doctrina constitucionalista ha propuesto varias teorías encaminadas a establecer el contenido esencial de los derechos fundamentales, estudio que excede de las pretensiones de esta investigación ${ }^{46}$. Aquí solo enunciaremos aquellas que han intentado compatibilizar su contenido con el juicio constitucional de proporcionalidad.

Frente a la tesis absoluta del contenido esencial que parte de la idea de que el contenido periférico puede ser afectado por una ley aunque fuese arbitraria o desproporcionada ${ }^{47}$, las tesis relativas mantienen una conexión entre el contenido esencial y la exigencia de justificación. Entre estas destaca la propuesta denominada "teoría mixta del contenido esencial" que conjuga los postulados básicos de la teoría especial absoluta con el principio de proporcionalidad, donde este último cumple la función, precisamente, de concretar la periferia de los derechos fundamentales y, de esta manera, la totalidad del contenido de los derechos fundamentales estaría fiscalizada jurídicamente ${ }^{48}$. Sin embargo, esta teoría ha sido criticada porque intenta integrar dos juicios de constitucionalidad incompatibles entre sí, además, se añade el problema de cómo delimitar entre el contenido esencial y periférico de un derecho fundamental y, sobre todo,

\footnotetext{
44 Bernal Pulido (2005) 479.

45 Un segundo grupo de teorías estructurales de concreción del contenido de los derechos fundamentales, junto con el juicio constitucional de proporcionalidad y las teorías del contenido esencial, son las denominadas teorías internas o de contenido reducido de los derechos fundamentales. Véase, De Otto y Pardo (1983) 138-140.

46 Por todos, Bernal Pulido (2005) 402 y ss.

47 Prieto Sanchís (2003) 232-233.

48 Parejo, Luciano (1982). "El contenido esencial de los derechos fundamentales en la jurisprudencia constitucional; a propósito de la sentencia del Tribunal Constitucional de 8 de abril de 1981", Revista Española de Derecho Constitucional, No 3, p. 172.
} 
no puede resolver un conflicto entre los contenidos esenciales de dos o más derechos fundamentales ${ }^{49}$.

Debido a los problemas que plantean las teorías espaciales del contenido esencial, se ha propuesto una dimensión sociotemporal, donde el contenido esencial debe identificarse con la cultura jurídica existente y, de una manera concreta, a través del propio juicio de constitucionalidad $^{50}$. Como puede advertirse, la crítica a esta teoría se ha centrado en la excesiva confianza en la objetividad de la cultura jurídica ${ }^{51}$. Esta posición, no obstante, se hace cargo de manera tácita del discurso como instrumento legitimante de las decisiones del TC como veremos más adelante.

Contrario a estas teorías, Alexy entiende que no tiene sentido tratar de encontrar en general un núcleo duro o esencial innegociable, sino que el contenido esencial se obtiene al final del proceso de argumentación en cada caso concreto y a la vista de los derechos o principios en pugna. En otras palabras, el contenido esencial es el resultado del juicio de ponderación ${ }^{52}$. Prieto Sanchís asume que el contenido esencial se conecta o muestra uno de los criterios de proporcionalidad en el siguiente sentido: "cuando más se sacrifica un derecho y, por tanto, cuando más nos acercamos a su núcleo o esencial -cualquiera que este sea-, mayor exigencia de justificación reclamará la medida limitadora y mayor ha de ser el peso y la importancia relativa del bien constitucional que se contrapone ${ }^{53}$.

Desde luego, el juicio constitucional de proporcionalidad no elimina la discrecionalidad presente en toda actividad interpretativa, sino que tan solo representa un esfuerzo destinado a racionalizar la aplicación de los principios y derechos constitucionales que, en no pocas ocasiones, son tendencialmente conflictivos ${ }^{54}$. Si consideramos a la Constitución, básicamente, como un conjunto de principios, se le puede achacar que fomenta la discrecionalidad en la justicia constitucional, pero como concluye Prieto Sanchís, por mucho que los principios suelan calificarse de vagos o inconcretos, lo cierto es que el principio de proporcionalidad ofrece pautas

Por todos, Bernal Pulido (2005) 428.

Jiménez Campos (1999) 24 y ss.

Por todos, Bernal Pulido (2005) 440 y ss.

Alexy (2007) 288. Bernal Pulido, por el contrario, no predica una completa identidad entre el contenido esencial y el principio de proporcionalidad. El contenido esencial no solo se vulnera cuando la injerencia en los derechos fundamentales resulta desproporcionada. Así, en los denominados casos fáciles la vulneración del contenido esencial no se establece a través del principio de proporcionalidad sino, simplemente, a través del principio de subsunción, Bernal Pulido (2005) 564. De este modo, el derecho de pertenecer a una asociación (art. 19. 15a inc. $3^{\circ} \mathrm{CPR}$ ) se concreta a través de la subsunción del caso concreto a la disposición iusfundamental y no como consecuencia de la aplicación del juicio de proporcionalidad.

53 Prieto Sanchís (2003) 236.

54 Prieto Sanchís (2003) 172. 
o estándares normativos allí donde antes solo existía la discrecionalidad o el arbitrio político ${ }^{55}$.

\section{2) EL JUICIO CONSTITUCIONAL DE PROPORCIONALIDAD Y PRINCI- PIOS PENALES COMO NORMAS ADSCRITAS IUSFUNDAMENTALES}

En los últimos años y, sin duda, como una consecuencia más del efecto de "irradiación" de la Constitución, se asiste a una reformulación y ampliación de los contenidos del principio de proporcionalidad en materia penal, a fin de aproximarlo a la estructura triádica con la que se aplica por parte de los tribunales constitucionales europeos. De hecho, ningún principio constitucional de los que afectan al sistema penal ha tenido en los últimos tiempos un auge tan extraordinario en el Derecho comparado. Así, en más de una resolución de los tribunales constitucionales europeos, e incluso en nuestra propia jurisprudencia constitucional ${ }^{56}$, se ha mostrado el poder argumentativo de este principio como límite al Ius puniendi, hecho que justifica la trascendencia que tiene para el derecho penal el estudio del principio de proporcionalidad.

Hasta tiempos recientes en el Derecho comparado buena parte de las argumentaciones jurídico-penales no han tenido en cuenta la dogmática de los derechos fundamentales, especialmente, referido al juicio constitucional de proporcionalidad ${ }^{57}$, a pesar de que su contenido y postulados esenciales han sido proclamados y desarrollados fragmentariamente a través de los principios de exclusiva protección de bienes jurídicos, lesividad, necesidad, utilidad y subsidiariedad, entre otros. El desarrollo de la dogmática de los principios y límites al ius puniendi ha adolecido de una falencia estructural a la hora de relacionarlos con los mecanismos de concreción de los derechos fundamentales. El principio y juicio de constitucionalidad por primera vez se hace cargo de esta situación. No obstante, la inclusión de los denominados principios penales y límites al ius puniendi al control constitucional de las leyes penales a través del juicio de proporcionalidad no está exenta de dificultades. Una de ellas pone en

\footnotetext{
55 Prieto SANChís (2003) 132.

56 En especial véase la STC Rol No 1.145-INA.

57 En Alemania, véase, Lagodny, Otto (2007). "El derecho penal sustantivo como piedra de toque de la dogmática constitucional”, trad. de Íñigo Ortiz de Urbina Jimeno, en Hefendehl, Roland: La teoría del bien jurídico. ¿Fundamento de legitimación del derecho penal o juego de abalorios dogmático?", Madrid: Marcial Pons, p.129. Sin embargo, en la doctrina chilena podemos encontrar algunos estudios sobre esta materia. Así, BAscuÑan Rodríguez, Antonio (2004). "Delitos contra intereses instrumentales", Revista de Derecho, No 1, Universidad Adolfo Ibáńez, pp. 323 y ss.; Oliver Calderón, Guillermo (2007). Retroactividad $e$ irretroactividad de las leyes penales, Santiago: Editorial Jurídica de Chile; Fuentes CubiLLos, Hernán (2008). "El principio de proporcionalidad en derecho penal. Algunas consideraciones acerca de su concretización en el ámbito de la individualización de la pena”, Ius et Praxis, vol. 14, No 2.
} 
evidencia el hecho de que la dogmática penal no suele tomar en consideración el tratamiento que realiza la teoría del derecho entre los principios y otros tipos de normas, en especial, las reglas. A lo anterior se añaden las distintas posiciones a la hora de sistematizar el principio de proporcionalidad en el conjunto de los principios y límites al ius puniendi. Así, en algunos planteamientos posee una autonomía propia, y en otros, por el contrario, se deriva de otros principios como el de lesividad, igualdad, etc. Pero en todo caso, en muchas ocasiones esta falta de claridad se ve mitigada por la consolidación que tienen en la dogmática penal ${ }^{58}$. Frente a la dispersión $y$, en ocasiones, reiterativo tratamiento de los principios penales limitadores del ius puniendi por parte de la dogmática, el principio de proporcionalidad integra el muy restrictivo grupo de principios, junto a los de legalidad, culpabilidad e igualdad que poseen un especial sustento constitucional ${ }^{59}$.

La necesaria relación entre el control constitucional de las leyes penales y los principios penales resulta especialmente problemática, no solo por la ausencia de un acuerdo mínimo sobre el contenido y ámbito de aplicación de los principios penales y límites al poder punitivo, sino también porque tampoco existe acuerdo sobre el propio contenido del principio de proporcionalidad y su relevancia en sede constitucional, ya que no debemos olvidar que en su elaboración y desarrollo por parte de la doctrina penal ha tenido, al menos hasta tiempos recientes, como principal referente al legislador. El problema radica, por tanto, en adaptar una terminología de procedencia constitucional a una asentada dogmática política criminal ${ }^{60}$.

A pesar de las anteriores dificultades, desde la perspectiva de la teoría de los derechos fundamentales, la doctrina no tiene mayores reparos en constatar que la justicia penal es un instrumento de poder de los Estados que necesariamente afecta de manera esencial a los derechos del individuo. La conexión entre derecho penal y derechos fundamentales es doble: en virtud de la pena, que limita la libertad personal; y en virtud de la conducta tipificada, que limita o circunscribe la esfera del legítimo ejercicio de derechos ${ }^{61}$. Con el injusto penal el legislador pretende reducir lo máximo posible la libertad de elección del individuo por tres motivos. El primero y obvio, por la amenaza de la pena; el segundo como consecuencia de la grave estigmatización del proceso y ejecución de la pena; y por último, por el interés que despierta al sujeto, por medio del refuerzo de la pena, interiorizar el desvalor ético del

\footnotetext{
58 Sánchez Martínez, Olga (2004). "Los principios en el Derecho y la dogmática penal”, Cuadernos Bartolomé de Las Casas, pp. 70 y ss.

59 Silva Sánchez, afirma en este sentido que estamos ante un principio de indudable base constitucional. Sílva SÁNCHez (1997) 320.

60 De la Mata Barranco (2007) 163.

61 Lagodny (2007) 130.
} 
injusto $^{62}$. En cuanto a la pena, se restringe la libertad personal para proteger mediante su imposición la prevención de los bienes jurídicos protegidos. Por tanto, el derecho penal se caracteriza frente a otras normas por reclamar la forma más fuerte de obligatoriedad y, por ello, por intervenir de manera intensa en la libertad del individuo. Por esta razón, necesita una justificación material especial frente a otros instrumentos de actuación del Estado ${ }^{63}$. Este salto cualitativo en la legitimación material del derecho penal en comparación con otras injerencias en los derechos fundamentales, se produce porque nuestra CPR al establecer una especial protección formal a través del principio de legalidad penal, demanda también una especial protección material a través, entre otros, del principio de proporcionalidad ${ }^{64}$.

Además, existen tres poderosos argumentos a favor de la adopción del juicio constitucional de proporcionalidad en materia penal. El primero radica en la potencia discursiva que se deriva de su aplicación por parte de tribunales constitucionales como el alemán y el español, entre otros, y del desarrollo doctrinal sin parangón que se ha producido en la Ciencia del Derecho. El segundo, como hemos mencionado, porque permite una sistematización de los principios y límites al ius puniendi desde la perspectiva de la teoría de los derechos fundamentales. En la doctrina penal se puede percibir una tendencia de utilizar el principio de proporcionalidad en sentido amplio como aglutinador de gran parte de los principios y límites penales, es decir, para identificar los contenidos de tutela del Derecho penal o incluso fundamentar aspectos relativos al sistema de responsabilidad o al sistema de penas ${ }^{65}$. Y el tercero, y quizá sea el argumento más importante, porque, por primera vez, se otorga una efectiva virtualidad práctica a los límites del ius puniendi y, en especial, a los principios de lesividad, ultima ratio, fragmentariedad, entre otros, en el control constitucional de la leyes penales. Aunque, a juicio de Hassemer, la doctrina de los derechos fundamentales, por su carácter reciente y actual, está menos elaborada teóricamente que las tradiciones penales, esta desventaja queda compensada por la capacidad de imponerse a través de los diferentes controles jurisdiccionales de control de constitucionalidad ${ }^{66}$.

62 Böse, Martin (2007). "Derechos fundamentales y Derecho penal como "derecho coactivo", en Hefendehl, Roland (ed.): Teoría del bien jurídico ¿Fundamento de legitimación del derecho penal o juego de abalorios dogmático?”, Madrid: Marcial Pons, p. 143.

63 Böse (2007) 144.

64 Desde la doctrina alemana: Schünemann, Bernd (2007). "El principio de proporcionalidad de bienes jurídicos como punto de fuga de los límites constitucionales de los tipos penales y de su interpretación”, en Hefendehl, Roland (ed.): La Teoría del bien juridico ¿Fundamento de legitimación penal o juego de abalorios dogmáticos?, Madrid: Marcial Pons, p. 211.

65 Díez Ripollés, José Luis (2003). Racionalidad de las leyes, Madrid: Trotta, p. 127.

66 Hassemer, Winfreid (2007). “¿Puede haber delitos que no afecten a un bien jurídico penal?”, en Hefendehl, Roland (ed.): La teoría del bien juridico. ¿Fundamento de legitimación del derecho penal o juego de abalorios dogmático?, Madrid: Marcial Pons, p. 97. 
También, resulta sugerente para el penalista la incorporación de valoraciones fácticas contenidas en el juicio de proporcionalidad, al menos, para a aquellos que consideramos a la Criminología como una ciencia auxiliar imprescindible a la hora de elaborar las categorías dogmáticas y político-criminales. Si los juicios de idoneidad y necesidad constituyen parámetros constitucionalmente necesarios en el control de las leyes, entonces es el ámbito penal, respaldado por la Criminología, donde los tribunales constitucionales deberían tener mayores posibilidades de éxito a la hora de realizar estas valoraciones empírico-sociales. Debemos recordar que no existe otra rama del ordenamiento jurídico que posea una ciencia empírico-social con el mismo desarrollo en influencia en las decisiones políticas y en las decisiones de los tribunales penales. Ahora bien, como veremos en el estudio de los juicios de idoneidad y necesidad, el conocimiento de la realidad criminal por parte de la Criminología está sometida a un serie de limitaciones de las que se debe hacer cargo el juicio constitucional de proporcionalidad.

Por último, los dos puntos de vistas que el TC debe tener presente para limitar la legitimidad democrática del legislador son la seguridad de las premisas empíricas y analíticas que evidencien la desproporción y la intensidad de la injerencia en el derecho fundamental. Pues bien, en cuanto a la primera, a priori, contamos con la Criminológica, que constituye la ciencia más desarrollada para determinar las premisas empíricas en el ámbito normativo; y en cuanto a los conocimiento analíticos y normativos también se encuentra con una dogmática penal y una ciencia política criminal que, a pesar de sus deficiencias, podemos concluir que poseen un nivel de primer orden en la Ciencia del Derecho. Y respecto a la segunda, nada más tenemos que recordar que constituye el medio de control social formal que afecta de manera más intensa los derechos fundamentales. Esto significa no solo una especial conexión entre el juicio de proporcionalidad y el derecho penal, sino también una especial obligación por parte del TC de un control material más intenso de proporcionalidad de las leyes penales. En otras palabras, el TC chileno deberá realizar un control más intenso de las leyes penales, especialmente, a través del recurso de inaplicabilidad ${ }^{67}$.

No obstante, los tribunales constitucionales han aplicado con extremada cautela el juicio constitucional en materia penal. Pero esta excepcio-

67 Así lo demuestra nuestra práctica jurisprudencial desde la reforma de 2005 que, salvo el requerimiento de constitucionalidad relativo al proyecto modificatorio de Ley 20.084, STS del 13 junio de 2007, Rol. 786, ha sustanciado todas las cuestiones constitucionales penales a través del recurso de inaplicabilidad. No obstante, esta situación, a mi entender, no se debe por el carácter concreto de este recurso, sino por el fenómeno del modelo penal de seguridad ciudadana que solo ha encontrado una cierta resistencia en parte del Poder Judicial y de la Defensoría penal pública. 
nalidad tiene su origen, además de en las propias tensiones entre el Poder Legislativo y el Poder constitucional, en un hecho previo que la estructura del juicio constitucional de proporcionalidad no tiene presente. Los partidarios del juicio de proporcionalidad establecen una relación negativa entre la norma legal -en este caso penal- y la afección de un derecho fundamental, de modo que pueda afirmarse, en palabras de Bernal Pulido, que "si la norma legal no existiera, entonces no se produciría la merma de la realización del derecho fundamental" 68 .

Esta relación causal negativa resulta incompleta e incorrecta. Incompleta porque no recoge toda la estructura jurídico-constitucional de una norma penal. Una norma penal, en primer lugar, se fundamenta en un conflicto social que presupone en la mayoría de la ocasiones una afección de un derecho fundamental. Pero además, resulta incorrecta que la ausencia de una norma penal conlleve también la falta de injerencia de un derecho fundamental, ya que no debemos olvidar que el derecho penal normativa $\mathrm{y}$, seguramente, fácticamente sustituye la justicia privada -como afección de un derecho fundamental- o en el mejor de los casos la racionaliza. En otras palabras el juicio de ponderación hace como si el conflicto social que subyace del delito no hubiera existido. El juicio de ponderación constitucional en materia penal tiene como primer presupuesto y, por tanto, fuera de su ámbito de aplicación, la previa lesión o puesta en peligro de un bien jurídico, hecho que, sin duda, afecta al juicio de proporcionalidad, en el sentido de justificar una mayor afección en los derechos fundamentales.

Como conclusión, se produce en palabras de Bunzel, el dilema constitucional del derecho penal: "el legislador parlamentario tiene, por una parte, como consecuencia de su prerrogativa de determinación de fines [y de la idoneidad y necesidad de la medidas públicas] un amplio margen en la creación de normas penales; por otra parte el Tribunal Constitucional exige, especialmente en un ámbito tan invasivo como el Derecho penal, que se tenga en cuenta de forma suficiente los preceptos constitucionales" ${ }^{69}$.

\section{1) LOS LÍMITES Y PRINCIPIOS PENALES COMO NORMAS ADSCRITAS}

Cada vez que el TC aplica los derechos fundamentales para resolver un caso cuya solución no emana directamente del Texto Constitucional, debe justificar de antemano el contenido normativo de su decisión. Este proceso recibe el nombre de concreción. La doctrina constitucional par-

\footnotetext{
68 Bernal Pulido (2005) 145.

69 Bunzel, Michael (2007). "La fuerza del principio constitucional de proporcionalidad como límite de la protección de bienes jurídicos en la sociedad de la información”, en Hefendehl, Roland (ed.): La teoría del bien jurídico. ¿Fundamento de legitimación del derecho penal o juego de abalorios dogmático?, Madrid: Marcial Pons, p. 155.
} 
tidaria del juicio constitucional de proporcionalidad disgrega la noción de derecho fundamental en disposición, norma y posición de derecho fundamental. La disposición de derecho fundamental hace referencia al enunciado constitucional que tipifica un derecho fundamental, por ejemplo, el art. 19. 2 CPR que prohíbe leyes arbitrarias; las normas de derecho fundamental es el conjunto de significados descriptivos de las disposiciones de derecho fundamental, constituye el resultado de la interpretación de estos enunciados constitucionales; el último elemento lo constituye la posición de derecho fundamental o derecho fundamental en sentido estricto $^{70}$, por ejemplo, el derecho de los homosexuales a ejercer la libertad sexual libremente consentida.

Respecto a su aptitud como sistema de interpretación constitucional, el juicio constitucional de proporcionalidad resulta idóneo para abordar uno de los principales problemas que plantea el control constitucional de las leyes: los propios preceptos constitucionales directamente poco aportan a la solución de un específico caso concreto. El propio lenguaje constitucional reproduce los consensos precarios en torno al contenido de los derechos a través de cláusulas deliberativamente abiertas, que dejan librada la fijación de su contenido definitivo al juego de las mayorías parlamentarias y a la interpretación judicial y, en último término, constitucional. Esta situación conlleva a que en el ámbito del control de constitucionalidad de las leyes se planteen con cierta frecuencia los denominados casos difíciles. Y son, precisamente, estos casos donde el principio de proporcionalidad encuentra su natural ámbito de aplicación. La necesidad de ponderación comienza desde el momento en que se acepta que no existen jerarquías normativas internas en la Constitución o, al menos, en parte de ellas.

El juicio constitucional de proporcionalidad parte de la lógica e inherente indeterminación normativa de los derechos fundamentales que, además, constituye una condición indeclinable para el funcionamiento del proceso democrático y adaptación del derecho al cambio de los tiempos $^{71}$. Parte, por tanto, de una concepción material en el control de constitucionalidad de las leyes en contraposición de una concepción formal o restringida a la vigilancia de los procesos democráticos. También, esta concepción material se aleja de posiciones dworkinianas sobre la concreción de los derechos fundamentales a través de principios morales. A mayor abundamiento el juicio de proporcionalidad constituye, de acuerdo con la denominada doctrina neoconstitucionalista, un criterio estructural para la concreción y fundamentación de los derechos fundamentales, en especial, para las denominadas normas adscritas de derecho fundamen- 
tal, es decir, aquellas normas de derecho fundamental que estatuyen un determinado precepto constitucional (disposición de derecho fundamental) y que el intérprete no puede conocer a priori. La indeterminación estructural de gran parte de los derechos fundamentales significa que pueden ser cumplidos de diversas maneras, satisfaciendo por completo el enunciado prescrito en los enunciados iusfundamentales. Las disposiciones de derecho fundamental rara vez son aptas para ser utilizadas como premisa mayor en el fundamentación interna de las decisiones de control de constitucionalidad de las leyes, debido a que, por una parte, las normas constitucionales se caracterizan por su alto nivel de abstracción y, por otra, los problemas que se plantean ante los tribunales constitucionales son tan matizados y concretos que desbordan la explicitud semántica de las normas directamente estatuidas. Por estas razones, el TC se ve en la necesidad de concretar una norma más específica (norma adscrita).

La mayoría de los denominados casos difíciles son tales, porque a la hora de resolverlos el intérprete no tiene claro cuál es el sentido de la norma que debe adscribir a la disposición de derecho fundamental. Así, una norma iusfundamental directamente estatuida como la prohibición de presumir de derecho la responsabilidad penal (art.19, No 3 inc. 6 ${ }^{\circ}$ CPR) se le puede adscribir la prohibición a no ser condenado en virtud de una mera responsabilidad objetiva o responsabilidad por resultado. Sin embargo, la necesidad de fundamentación de las normas adscritas no significa que sean únicamente producto de la interpretación, sino que son normas que están dotadas de una validez prima facie, validez que dimana de la propia Constitución. Por tanto, la tipificación constitucional de una disposición de derecho fundamental implica no solo la validez de las normas que estatuye directamente, sino también la validez prima facie de las normas adscritas.

Las normas adscritas también son actualizadas por las demás fuentes de los derechos fundamentales: los tratados internacionales en el ámbito de los derechos humanos suscritos por Chile, los reglamentos y, sobre todo, la legislación. El legislador puede determinar dos tipos de normas adscritas. Las primeras son aquellas que la propia norma iusfundamental estructura de tal manera que se permiten varias opciones políticas. En estos casos, la norma adscrita no vincula constitucionalmente al legislador. En las segundas, por el contrario, el legislador no dispone de esta libertad, sino que es fiscalizada por el propio TC en el control de constitucionalidad de las leyes.

La principal crítica que se puede realizar a las normas adscritas es, precisamente, su propio estatus de normas jurídicas. Los fundamentos jurídicos de los fallos del TC constituyen, valga la redundancia, fundamentaciones, pero ningún caso normas jurídicas. Así, acorde con esta crítica las normas adscritas serían enunciados interpretativos o, simplemente, interpretaciones de los enunciados de derecho fundamental. 
En principio, la concreción de las normas adscritas viene establecida por las denominadas teorías materiales de los derechos fundamentales (liberal, democrática y socialdemócrata). Los criterios materiales, por sí solos, son insuficientes para concretar las normas adscritas por el hecho de que estas teorías suelen entrar en colisión. Por esta razón, se han establecido varios criterios estructurales, dentro de los cuales sobresalen: la concreción del contenido esencial, las denominadas teorías internas y el principio de proporcionalidad ${ }^{72}$. El juicio constitucional de proporcionalidad resulta especialmente apto para la correcta fundamentación de los denominados casos difíciles, en concreto en los casos de conflictos entre derechos fundamentales. El juicio constitucional de proporcionalidad debe ser entendido como un criterio estructural que pretende determinar el contenido de los derechos fundamentales vinculantes, especialmente, para el legislador ${ }^{73}$.

La mayoría de los principios y límites al ius puniendi no se encuentran expresamente reconocidas en nuestra CPR, así como en la mayoría de los textos constitucionales. Esto significa que estos principios para que tengan validez constitucional deben ser incorporados como normas adscritas. Así, a modo de ejemplo, Lopera Mesa define los principios penales y fines de la pena como mandatos de optimización, de acuerdo con la concepción de Alexy, es decir, "normas que ordenan que algo sea realizado en la mayor medida posible, dentro de las posibilidades jurídicas y reales existentes", a diferencia de las reglas, que "contienen determinaciones en el ámbito de lo fáctica y jurídicamente posible"74.

Los principios limitadores al ius puniendi regulados en la CPR resultan más bien escasos. Junto al principio de legalidad y el mandato de tipicidad (art. 19.3 ${ }^{\mathrm{a}}$, inc. $8^{\circ}$ y $9^{\circ}$ ), encontramos la prohibición de presumir de derecho la responsabilidad penal (art. 19.3으. inc. 6º ), la exclusión general de la pena de confiscación y las garantías procesales recogidas en el art.19. $7^{\circ}$ c) y la exigencia de quórum calificado para establecer la pena de muerte (art.19. $1^{\circ}$, inci. $3^{\circ}$ ). El TC ha incluido otros principios limitadores a través de la cláusula general del inc. $2^{\circ}$ del art. $5^{\circ}$, como por ejemplo, la prohibición de penas inhumanas y la exclusión de la prisión por deudas ${ }^{75}$. A partir de lo anteriormente señalado a través de las denominadas normas adscritas nuestro Tribunal Constitucional tiene como cometido establecer qué principios y límites penales se pueden incorporar a las disposiciones o normas de derecho fundamental y, de esta manera, configurar un sistema de precedentes en el control constitucional de las leyes penales.

Bernal Pulido (2005) 129-130.

Por todos, Bernal Pulido (2005) 401.

Lopera Mesa (2006) 276.

STC de 6-8-2009, Rol No 1.328-09-INA. 
De acuerdo con Bernal Pulido, el juicio constitucional de proporcionalidad no tiene la capacidad de operar sin una disposición iusfundamental que le sirva de fundamento, es decir, constituye un instrumento metodológico para concretar los límites que las propias disposiciones constitucionales imponen a la acción legislativa ${ }^{76}$. La cuestión que se suscita es qué lugar ocupan los denominados límites al ius puniendi en el control constitucional de las leyes que no se encuentran expresamente consagrados en la CPR. A la vista de la estructura y contenido del principio de proporcionalidad en sentido amplio, los principios y límites al ius puniendi pueden considerarse como normas adscritas a derechos fundamentales o pueden formar parte del propio el juicio constitucional de proporcionalidad. Como normas adscritas, por ejemplo, la doctrina nacional ha vinculado el principio de culpabilidad penal a varios preceptos constitucionales (arts. 1 , incs. $1^{\circ}$ y $4^{\circ}$ y $19 . N^{\circ} 3$, inc. $6 \mathrm{CPR}^{77}$ ). Como parte del contenido del juicio constitucional de proporcionalidad, claramente, podemos incluir los principios de lesividad y necesidad.

\section{3) EL CONTENIDO DEL JUICIO DE PROPORCIONALIDAD: EL INJUSTO Y LA PENA}

El juicio de proporcionalidad debe comenzar por determinar qué parte de la norma penal está cuestionada constitucionalmente. Partiendo con la diferenciación entre injusto y pena, las intromisiones deben ser valoradas a la luz de distintos derechos fundamentales. En el caso de que la prohibición pueda afectar a una libertad específica (la libertad sexual, la libre elección de profesión, etc.) la norma de sanción autoriza a las autoridades del sistema de justicia criminal a dos clases de intromisiones: a efectuar un reproche estatal (declaración de culpabilidad) y a imponer sanciones específicas. En el caso de que se someta a control tanto el injusto como la pena, el TC deberá, de acuerdo con la misma lógica que impera en la Teoría jurídica del delito, examinar primero la norma de conducta. Si el injusto resulta inconstitucional, no será necesario continuar con el examen de la consecuencia jurídica. Si, por el contrario, esta resulta acorde con la Constitución, habrá que continuar con el examen de la norma de sanción ${ }^{78}$.

El juicio de proporcionalidad presupone la diferenciación de las normas constitucionales entre principios y reglas. Estaremos ante un principio cuando nos enfrentemos ante una norma jurídica especialmente apta para introducir en el ordenamiento jurídico criterios axiológicos, sin per-

\footnotetext{
76 Bernal Pulido (2005) 528.

77 Véase un estudio sobre la doctrina comparada y nacional en: KüNSEMüLLER, Carlos (2001). Culpabilidad y pena, Santiago: Editorial Jurídica de Chile, pp. 19-27.

78 BösE (2007) 145.
} 
juicio de que esta concepción axiológica no esté muy en consonancia con las exigencias de taxatividad y seguridad jurídica que presiden el derecho penal. La adscripción prima facie en el ámbito de protección de un derecho fundamental conlleva una importante consecuencia argumentativa: es el legislador a quien le compete la carga argumentativa de justificar la medida, en este caso, penal $^{79}$.

\section{1) PRESUPUESTOS DE APLICACIÓN: LA EXISTENCIA DE UN FIN LEGÍTIMO CONSTITUCIONAL Y UN CONFLICTO ENTRE PRINCIPIOS}

\section{(3.1.1) La existencia de un fin legítimo constitucional (el principio de lesividad)}

Conviene señalar que el fin perseguido no forma parte propiamente del test de proporcionalidad, ya que este considera la existencia de un fin legítimo y, por tanto, solo cuestiona los medios para su consecución y su proporcionalidad (en sentido estricto). La constitucionalidad de los fines perseguidos deberá ser controlada anteriormente, es decir, como presupuesto al juicio de proporcionalidad, en la que deberá comprobarse si se trata de un interés legitimado constitucionalmente y si el órgano estatal que actúa tiene la competencia atribuida en esa materia ${ }^{80}$.

El término "fin constitucionalmente legítimo" en términos penales puede hacer referencia a los fines de la pena o a la legitimidad de los bienes jurídicos protegido. Si el juicio se centra en la norma de conducta se deberá prestar atención a la constitucionalidad del bien jurídico protegido; en el caso de la pena deberemos centrarnos en los fines esta, sin perjuicio que en el juicio de proporcionalidad (ponderación) en sentido estricto se deba tener presente la lesión o puesta en peligro del bien jurídico protegido. Ahora bien, tenemos que recordar que la constitucionalidad de la finalidad de la norma penal no se debe circunscribir a los fines de la pena y al bien jurídico, sino a la totalidad de las normas constitucionales; por ejemplo, el principio de igualdad podría fundamentar una finalidad constitucionalmente ilegítima, como por ejemplo, el injusto del art. 365 CP.

Lagodny, manifiesta, quizá de manera exagerada, que la discusión sobre los fines de la pena no interesa en lo más mínimo a la doctrina constitucionalista. Si la pena es idónea, necesaria y proporcionada, no

\footnotetext{
79 Prieto Sanchís, Luis (2000). "La limitación de los derechos fundamentales y la norma de clausura del sistema de libertades", Revista del Instituto Bartolomé de Las Casas, No 8, pp. 441 y ss.

80 Kluth, Winfried (1998). "Prohibición de exceso y principio de proporcionalidad en el derecho penal alemán”, Cuadernos de Derecho Público, No 5, p. 226.
} 
existe problema constitucional alguno ${ }^{81}$. A mi entender, esta falta de atención sobre la constitucionalidad de los fines perseguidos por la pena, se debe a que los fines preventivos y retributivos constituyen la esencia de la irracionalidad estructural de todo Estado de Derecho que el TC no está en condiciones de controlar, al menos, en este momento. Ahora bien, las formas de cumplimiento de las penas los tribunales constitucionales han establecido una serie de límites constitucionales. Nos referimos a la prohibición de torturas y tratos inhumanos e, incluso, las penas con fines exclusivamente inocuizadores. Tampoco, la legitimidad constitucional del bien jurídico protegido, a pesar de una estrecha conexión con el juicio de proporcionalidad, no ha existido en la cotidianeidad del debate parlamentario ni constitucional. ${ }^{82}$

El juicio de proporcionalidad pretende cumplir esta función en el sistema constitucional. El principio de lesividad, como presupuesto del juicio constitucional de proporcionalidad, tiene el papel fundamental del establecimiento de normas adscritas a un derecho fundamental. Ahora la cuestión es qué bienes jurídicos legitima la Constitución y de qué manera se determina esa compatibilidad constitucional. Esta concreción debe realizar a través de una conexión de los bienes jurídicos con los derechos y garantías fundamentales.

El principio de exclusiva protección de bienes jurídicos afecta transversalmente al juicio constitucional de proporcionalidad: como parámetro a la hora de determinar la legitimidad constitucional del fin perseguido por la norma penal, como parte del contenido del juicio de idoneidad y necesidad y como factor que debe sopesarse en el juicio de proporcionalidad en sentido estricto. La incidencia del principio de lesividad en el juicio constitucional de proporcionalidad, Lascuraín Sánchez encuentra su antecedente dogmático penal más directo en las condiciones que en su día estableció Mayer para que un bien jurídico pueda ser protegido penalmente: que sea digno de protección, con capacidad para protegerlo y necesitado de protección ${ }^{83}$. En este sentido, Díez Ripollés teme que el principio de proporcionalidad se convierta en un nuevo fetiche conceptual, omnicomprensivo y encargado de sustituir o de poner en un segundo plano al del bien jurídico ${ }^{84}$. Pero, más bien, este temor se ve sustancialmente mitigado si se considera que el juicio constitucional de proporcionalidad reproduce los aspectos centrales de la teoría del bien jurídico.

La jurisprudencia del TC no ha establecido hasta el momento un concepto de bien jurídico como presupuesto o condición del juicio cons-

\footnotetext{
81 Lagodny (2007) 133.

Hassemer (2007) 96.

LASCURAÍn SÁNCHEZ(1998) 188.

DíEz Ripollés (1998) 131.
} 
titucional de proporcionalidad ${ }^{85}$. A lo sumo, el TC ha reducido los frutos de la teoría del bien jurídico a un nivel de información y de justificación de la intervención penal. Así, Schünemann reprocha al TC alemán el haber depreciado la potencia crítica de la teoría del bien jurídico, a pesar de que en la Ley Fundamental encuentran muchos motivos para su recepción. El principio de protección de bienes jurídicos se encuentra anclado en la base conceptual del Pacto Social, el cual también se presupone en la Ley Fundamental y de su fundamento histórico ${ }^{86}$. Stächelin, postula que el bien jurídico se integra informalmente o de manera implícita en la prohibición de exceso jurídico constitucional ${ }^{87}$. De esta manera, se puede decir que la reconstrucción jurídico-penal de la prohibición de exceso no sería posible de ningún modo sin la teoría del bien jurídico. El bien jurídico supone para Hassemer la esencia de la justificación de una prohibición de acción. Una prohibición de acción jurídico-penal en forma de una disposición penal no se justifica cuando no se puede elegir para alcanzar convenientemente la finalidad reconocida que no es otra que la protección originada a través del derecho penal por el bien jurídico de lesión o de peligro ${ }^{88}$. Roxin, en el mismo sentido, afirma que el concepto bien jurídico es deducido de las funciones del derecho penal que, por una parte, desarrollan los elementos del Contrato Social de nuestra Constitución y, por otra, delimitan las fronteras de la violencia estatal ${ }^{89}$. Incluso, un escéptico del bien jurídico protegido, como Lagodny mantiene ahora en relación a las funciones político criminales de los derechos fundamentales que "el mérito de la discusión jurídico penal sobre el bien jurídico consiste en haber encontrado una dirección de pensamiento con la cual, al menos teóricamente, puede ser llevada en la necesitad de fundamentación por parte del legislador ${ }^{90}$.

Quizá la teoría del bien jurídico que se acomoda mejor al control constitucional de proporcionalidad es la denominada "concepción per-

85 En el mismo sentido así lo manifiesta Roxin respecto de la jurisprudencia constitucional alemana. Roxin, Claus (2006). Strafrecht Allgemeiner Teil, vol. I, $4^{\mathrm{a}}$ ed., München: C.H. Beck, p. 40. Tampoco en Italia a pesar de las distintas formulaciones de la Corte Constitucional no difiere sustancialmente a la situación en Alemania. Palazzo Francesco (1998). "Offensività e ragionevolezza nel controllo di costituzionalità sul contenuto delle leggi penali”, RIDPP, p. 350. No obstante, la jurisprudencia del TC español entiende como un prius lógico del juicio de proporcionalidad el bien jurídico que se pretende tutelar, a fin de establecer si su protección no solo está proscrita constitucionalmente, sino también si socialmente resulta irrelevante SsTC 111/1993, 55/1996, 161/1997.

86 SCHÜNEMANN (2007) 220.

87 STÄCHELIN, Gregor (1999). "Es compatible la "prohibición de infraprotección” con una concepción liberal del derecho penal”, trad. de Felip Saborit, en VV. AA: La insostenible situación del derecho penal, Granada: Comares, p. 295.

Hassemer (2007) 99.

Roxin (2006) 42.

LAGODNY (2007) 87. 
sonal del bien jurídico" defendida por Hassemer, entre otros. Como es conocido, los bienes jurídicos estrictamente individuales y los supraindividuales, en la medida que puedan justificarse a partir de algunos de los bienes individuales, constituyen los únicos que merecen una protección jurídico penal. Es decir, el derecho penal se encuentra legitimado constitucionalmente en la medida que proteja mediata o inmediatamente bienes jurídicos individuales ${ }^{91}$.

La inclusión de bienes jurídicos supraindividuales o macrosociales conlleva el peligro de privarle de la función de control constitucional de las leyes penales. Los injustos penales anticipados a los bienes jurídicos individuales, que no suponen el aseguramiento de las condiciones inmediatas del desarrollo de la persona, no son, en cuanto delitos de peligro, per se inconstitucionales, pero sí están especialmente precisados de legitimación. La inclusión de bienes jurídicos supraindividuales, principal campo de cultivo de la tensión entre libertad y seguridad, puede llevar a último término a la sustitución de la función crítica y limitadora del bien jurídico por la mera protección de sentimientos. Si se despojara a los bienes de peligro abstracto de la conexión de protección de desarrollo personal, el derecho penal dejaría de ser un medio de protección de bienes jurídicos para convertirse en un instrumento de conducción social ${ }^{92}$.

La teoría del bien jurídico como fundamento de la finalidad constitucional de la medida penal debe ser entendida en su dimensión negativa, es decir, no como directriz obligatoria en la configuración de las leyes penales, sino como fundamento para excluir ciertas conductas del ordenamiento jurídico. La dogmática penal ha establecido dos grandes límites. El primero de ellos, radica en la necesidad de una finalidad, interés u objeto de protección de carácter material. En este sentido el derecho penal no protege normas por el solo hecho de su validez formal. Así, el TC alemán parte de que la simple desobediencia no puede justificar la pena ${ }^{93}$. La segunda se centra en la inadmisibilidad de la protección de la moral o de una determinada ideología. Es decir, de conductas realizadas por adultos con recíproco acuerdo y sin afectar, al menos significativamente, a otros derechos ni a Estados vulnerables protegibles 94 . A modo ejemplo, nuestro vergonzoso art. $365 \mathrm{CP}$ constituye un claro precepto inconstitucional debido a la finalidad perseguida: la protección de una determinada moralidad sexual, siendo innecesario continuar con el juicio constitucio-

\footnotetext{
91 Hassemer, Winfried (1989). "Lineamientos de una teoría personal del bien jurídico", $D P$, No 46, pp. 275-285.

92 Sternenberg-Liben (2007) 114.

93 BverfGE 80, 244 (256); 90, 145(184), citadas por: Böse (2007) 138.

94 Por todos Roxin, Claus (2006). Derecho penal. Fundamentos. La estructura juridica del delito, trad. de Diego Luzón Peńa, Miguel Díaz y García y Javier de Vicente, Madrid: Civitas, p. 52 .
} 
nal de proporcionalidad. La exclusión de las meras inmoralidades de la protección penal también se ve reforzada por la desigualdad que, claramente, produce, si se limita el contenido del art. 19. $2^{\circ} \mathrm{CPR}$, de acuerdo con nuestro TC, a "la edad, sexo, origen social o nacional del sujeto activo o su pertenencia a otra categoría que pudiera resultar inaceptable para la diferencia de que se trata, como sería la condición social, posición económica o creencias del responsable del delito" 95 .

\section{(3.1.2) Un conflicto entre principios: la relación entre el derecho a la seguridad y el derecho a libertad}

En el control de constitucionalidad de las leyes penales se reproduce la tensión inherente que se origina en la creación de las normas penales: la protección de bienes jurídicos y la garantía de los derechos fundamentales. Nos encontramos ante finalidades que, pudiendo convivir en el plano de validez, resultan tendencialmente contradictorias en su aplicación práctica sin que resulten eficaces o convincentes los medios tradicionales de resolución de antinomias ${ }^{96}$. Si bien resulta discutible encontrar principios del mismo valor en la CPR, en el ámbito de la política criminal puede ser uno de los supuestos donde se aproxime más a este presupuesto ideal del juicio de proporcionalidad. En realidad el resultado óptimo de un ejercicio de ponderación no se materializa con un triunfo aplastante de unos de los principios en el caso concreto, sino en la armonización de ambos ${ }^{97}$. La provisión de seguridad es considerada, junto a la racionalidad o proporcionalidad, una de las bases del moderno Estado liberal. Los derechos fundamentales como derechos objetivos no solo se deriva la obligación de omitir por principio injerencias en las libertades y bienes de los ciudadanos, sino también la obligación de proteger tales bienes y libertades de ataques provenientes de otros ciudadanos, es decir, seguridad a través del Estado. De aquí se sigue que el establecimiento de sanciones penales destinado a la paz jurídica no puede pretenderse a cualquier precio ni consistir en la consecución cualquier finalidad que se le ocurra al legislador. El deber estatal de protección e, incluso, las supuestas obligaciones constitucionales de incriminación deben fundamentarse en el aseguramiento de la libertad ciudadana, sea a través del aseguramiento de la libertad individual o de forma mediata a través de unidades funcionales (bienes jurídicos macrosociales).

Ahora bien, resulta discutible que ante un juicio de ponderación se pueda llegar a una armonía absoluta entre ambos principios en conflicto, en realidad, significa que la preponderancia en concreto de unos de ellos

STC de 7 de mayo de 2009, Rol No 825, Considerando Noveno.

Por todos, Prieto Sanchís (2003) 186.

Prieto Sanchís (2003) 192. 
debe tomar en consideración (ponderar) el otro principio en conflicto. Cuando más se aleje la conducta incriminada de tal referente personal, tanto mayores habrán de ser las exigencias en lo que respecta al valor del bien (mediato) personal protegido y al grado de peligro material. De este modo al legislador penal, como hemos manifestado con anterioridad, se le impone un especial deber de motivación ${ }^{98}$.

El denominado derecho penal de seguridad o modelo penal de seguridad ciudadana -que comprende fenómenos no solo como el terrorismo o el tráfico de drogas, sino también la agravación de bienes jurídicos individuales como la propiedad- ha otorgado mayor peso, valga la redundancia, a las necesidades de seguridad ciudadana frente a la protección de las libertades individuales. Este modelo considera al hombre no como un individuo, sino como un elemento intercambiable en un mundo por principio peligroso. Así, se percibe una nueva perspectiva donde, por una parte, el individuo va perdiendo su concreta cualidad de protección constitucional y, por otra, una nueva definición y justificación de las facultades estatales derivada de los intereses de seguridad ${ }^{99}$. El peligro ya no se basa en el autor individual, sino en un estado de amenaza permanentemente difuso. Ya no estamos ante derechos individuales que deben relacionarse con las injerencias en los derechos fundamentales, sino estamos ante intereses de seguridad que son tratados como derechos colectivos. El individuo como parte de la sociedad comparte su estatus de libertad y, consecuentemente, si la libertad de la sociedad es amenazada debe aceptar intromisiones o injerencias en su propia libertad individual, en otras palabras, la protección de la seguridad sirve, en último término, para salvaguardar la libertad social. Esta relación entre seguridad y libertad afecta a los derechos de las minorías: el individuo ya no es visto como un individuo autónomo que realiza conductas autorresponsables que son protegidas jurídicamente, sino que es entendido como una parte anónima de la sociedad y posee como parte de la seguridad colectiva una libertad general.

Por tanto, la desindividualización de la libertad conduce a una merma en la protección constitucional de los derechos individuales ${ }^{100}$. Las injerencias en los derechos fundamentales asentados en el bien jurídico seguridad, pueden justificarse si este bien jurídico resulta superior al afectado por la ley penal. Esta justificación se realiza a través de construcción teórica de protección mediata de los derechos fundamentales como la

\footnotetext{
98 Sternenberg-Liben (2007) 115.

99 Lepsius, Oliver (2001). "Das verhältnis von Sicherheit und Freiheitsrechten in der Bundesrepublik Deutschland nach dem 11. September 2001”. Disponible en http://aicgs.org/ documents/lepsius.pdf, p. 16 [Fecha de visita: 15 de abril de 2010].

100 La relación entre libertad y seguridad ha sufrido un cambio fundamental tras el ataque terrorista del 11 de septiembre que ha supuesto una aceleración en este proceso de desindividualización. Lepsius (2001) p. 17.
} 
libertad, vida e integridad física etc., a través de bienes jurídicos como seguridad nacional, vial o salud pública.

El control constitucional de las leyes penales no puede concebirse al servicio de la consecución de los intereses públicos, sino que tanto el injusto como la pena deben considerarse como un sacrificio sobre el que pesa una carga de justificación especial.

\section{(3.1.3) El juicio de idoneidad: el principio de utilidad en un Estado social}

Establecidos como legítimos los principios constitucionales en conflicto, el primer juicio de proporcionalidad radica en la idoneidad de la medida. El requisito de idoneidad exige que tanto el injusto como la consecuencia jurídica sean aptos para alcanzar el fin o protección del bien jurídico que les fundamenta ${ }^{101}$. Estamos ante un claro criterio de racionalización instrumental, es decir, que la restricción de los derechos fundamentales se suponga útil para logar el fin perseguido, además, presupone una naturaleza gradual y empírica ${ }^{102}$. Este requisito de racionalidad es denominado por la dogmática penal como el principio de utilidad de la intervención penal, que se fundamenta, de acuerdo con Mir Puig, en el Estado social: el derecho penal se legitima socialmente cuando su intervención se muestra útil ${ }^{103}$. Esta problemática, es decir, la ausencia de virtualidad práctica de la medida, es tratada por la doctrina penal a través del denominado derecho penal simbólico.

Las conductas socialmente dañosas dependen decisivamente del conocimiento empírico sobre tal lesividad. Desde una perspectiva político criminal estamos ante una manifestación del denominado principio de correspondencia con la realidad social.

Nos enfrentamos ante un mandato de optimización referido al legislador, y la cuestión es si de acuerdo con el principio de autonomía políti-

101 Cuerda Arnau, María Luisa (1997). “Aproximación al principio de proporcionalidad en derecho penal”, en VV. AA: Estudios jurídicos en memoria del profesor Dr. José Ramón Casabú Ruiz, Valencia: Universitat-Instituto de Criminología, pp. 496 y ss.

102 De acuerdo con Lascuraín el juicio de idoneidad constituye un presupuesto al genuino juicio de proporcionalidad. Puede cuestionarse el juicio de idoneidad como un juicio de proporcionalidad (externo), al contrario de como sucede, como veremos a continuación, con el juicio de necesidad. Más bien, como postula Lascuraín, estamos ante un presupuesto del juicio constitucional como el de constitucionalidad de la finalidad de la norma. Aquí no se compara nada, sino que simplemente se establece la idoneidad cualitativa para alcanzar el fin normativo: sin esta calidad instrumental no resulta ya necesario realizar un juicio de proporcionalidad tanto externo como interno. Si una norma resulta inidónea no estamos ante un juicio de proporcionalidad porque se ha producido un "intercambio de libertad por nada de libertad". Lascuraín (1998) 167.

103 Mir Puig, Santiago (2002). Derecho penal. Parte General, 6a ed., Barcelona: Reppertor, p. 121. 
ca debe ser evaluado en sede constitucional y, en su caso, con qué intensidad. La tradicional concepción del control de constitucionalidad de las leyes entiende que solo resulta posible realizar una simple comparación entre normas, y por tanto, no es necesario e, incluso, prohibido juicios de índole empírico o controles sobre la eficacia de la norma enjuiciada. En cambio, una creciente corriente doctrinal, avalada por algunos fallos en el derecho comparado, estima necesaria un juicio sobre la idoneidad de la ley. La importancia de las premisas empíricas en el juicio de idoneidad tiene como presupuesto político la función de garantía en las intervenciones del Estado en los derechos fundamentales de la persona, cuya afectación debe ser justificada socialmente. Ahora bien, este juicio no está exento de problemas. Además de atentar contra el margen epistémico del legislador que le asiste en razón de su legitimidad democrática, se ve afectado por las intrínsecas limitaciones de las ciencias sociales a la hora de pronosticar los efectos de una acción legislativa ${ }^{104}$.

Debido a estas razones, la mayoría de la doctrina y parte de la jurisprudencia constitucional comparada tienden a inclinarse por una versión débil del examen de idoneidad, en el sentido de admitir que satisfacen este requisito todos aquellos medios que presenten alguna contribución positiva al logro del fin legislativo, sin reparar si los mismos solo reportan una satisfacción mínima y parcial del objetivo propuesto, o en la rapidez o probabilidad con la que la medida llega a surtir efecto ${ }^{105}$. En otras palabras, una medida adoptada por una intervención legislativa en un derecho fundamental no es idónea, cuando no contribuye de ningún modo a la obtención de un fin inmediato ${ }^{106}$. Una disposición penal es inidónea si puede ser considerada de manera inequívoca desde el momento de su promulgación como inútil para la finalidad perseguida ${ }^{107}$, o para un caso concreto en el caso de nuestro recurso de inaplicabilidad.

Sin perjuicio de las razones aducidas a favor de una versión débil del juicio de idoneidad, en los casos que se someta a control constitucional una pena, los tribunales constitucionales pueden solventar este juicio y, de hecho así lo hacen, afirmando los efectos preventivos que toda pena produce $^{108}$. Por tanto, resulta difícil que el TC pueda declarar inconstitucional una intervención penal, más cuando una parte importante de la Criminológica otorga un limitado efecto preventivo a las penas, es decir,

\footnotetext{
104 Véase un panorama general sobre las limitaciones de la ciencia criminológica en FernáNDez Cruz, José Ángel (2009). "La legitimidad social de las leyes penales: límites y ámbito de aplicación”, Revista de Derecho de la Pontificia Universidad Católica de Valparaíso, vol. XXXIII, pp. 232-259.

105 Lopera Mesa (2006) 455.

106 Bernal Pulido (2005) 720.

107 BvergGE 38, 210, 230.

108 Véase el Considerando vigésimo primero de la STC de 7 de marzo de 2008, Rol No 825.
} 
una limitada idoneidad ${ }^{109}$. Respecto de la norma de conducta, SternbergLieben asegura que una conducta, a efectos constitucionales, resulta idónea siempre y cuando exista un bien jurídico del lado de la víctima que resultaría afectado por el injusto penal ${ }^{110}$.

Ahora bien, establecida la necesidad de un control constitucional sobre la idoneidad de la ley penal, queda por determinar con qué criterios empíricos debe realizarse este juicio entre medios y fines, juicio que resulta especialmente problemático en los delitos de peligro abstracto. Como pone de manifiesto Díez Ripollés, en el caso del TC espańol, pero perfectamente extrapolable a nuestro TC, brillan por su ausencia criterios que pudieran resultar operativos a la hora de verificar este juicio de idoneidad, como por ejemplo, recursos disponibles, experiencias tanto nacionales como comparadas, etc. ${ }^{111}$. El derecho penal, como medio de control social, se imbrica con múltiples mecanismos de control social formales e informales, y esto hace que se dificulte la determinación de su grado de idoneidad. También debemos tener presente los condicionantes de la propia evaluación de los índices de prevención, detención y sanción de la norma penal. La prerrogativa del legislador para examinar la idoneidad de la medida, donde el TC solo puede fiscalizar aquellas que resultan absolutamente inidóneas, junto a la constatación de la falta de medios para acceder a la información criminológica, esencialmente imperfecta, conlleva a que el examen de la idoneidad de la protección penal a duras penas pueda cumplir su función limitadora. A lo anterior debemos ańadir si debe incluir exclusivamente los efectos y beneficios manifiestos de la norma o, por el contrario, debe comprender los no manifiestos o latentes.

\section{(3.1.4) El juicio de necesidad: el principio de mínima intervención y subsidiariedad}

El juicio de necesidad requiere acreditar que no exista otra medida que, obteniendo en términos semejantes la finalidad perseguida, resulte menos gravosa o restrictiva. Estamos ante una manifestación tanto de la racionalidad ética fundamentada en el principio del dańo, es decir, que la restricción de los derechos fundamentales sea lo más moderada posible; como también de la racionalidad instrumental, ya que debe ser avalada empíricamente con otras medidas igualmente idóneas.

El principio de necesidad es tratado por la doctrina penal bajo la idea

\footnotetext{
109 Véase una recopilación de los diferentes estudios sobre los efectos preventivos de las penas en Serrano Maíllo, Alfonso (2009). Introducción a la Criminología, 6a ed., Madrid: Dykinson, pp. 283-336.

110 STERnENBERG-LibEN (2007) 121.

111 Díez Ripollés, José Luis (2005). "El control de constitucionalidad de las leyes penales”, en Revista Española de Derecho Constitucional, No 75, p. 63.
} 
del carácter subsidiario y fragmentario del derecho penal. De hecho, en la dogmática penal relativa a la teoría del bien jurídico son muchos los autores que se refieren directamente al requisito de necesidad ${ }^{112}$.

El examen de necesidad requiere analizar, en primer lugar, si existen medios equivalentes, por lo menos, de una misma idoneidad a la de la medida para contribuir a alcanzar el fin constitucionalmente legítimo desde todas las perspectivas posibles, de entre las que destacan: la eficacia, la temporalidad y la probabilidad del fin. En segundo lugar, requiere que el medio alternativo de igual o superior idoneidad intervenga con menor intensidad en el derecho fundamental ${ }^{113}$.

El juicio constitucional de proporcionalidad, como hemos manifestado, se adecua mejor a un control concreto que a uno abstracto de proporcionalidad. Esta aseveración se confirma en el juicio de necesidad, ya que el TC posee una mayor información para determinar la necesidad de la medida ${ }^{114}$.

El juicio de necesidad plantea la cuestión hasta dónde resulta razonable indagar sobre el posible elenco de medidas igualmente idóneas ${ }^{115}$. Este juicio requiere una cierta argumentación prospectiva que se acomoda mal al modelo de juez pasivo de nuestro sistema, por esta razón, el legislador goza de un amplio margen de apreciación. No obstante, como pone de manifiesto la sentencia del TC español 55/1996 "si solo a la luz del razonamiento lógico, de datos empíricos no controvertidos y del conjunto de sanciones que el mismo legislador ha estimado necesarios para alcanzar los fines de protección análogos, resulta evidente la manifiesta suficiencia de un medio alternativo menos restrictivo de derechos para la consecución igualmente eficaz de las finalidades perseguidas por el legislador, podría procederse a la expulsión de la norma" 116 .

Cuando las medidas alternativas no hayan superado el examen del juicio de necesidad, pueden, sin embargo, tener un peso importante en el juicio de proporcionalidad estricto. Así, por ejemplo, cuando la medida alternativa resulta más idónea o menos restrictiva de los derechos fundamentales en alguna o, incluso, en la mayoría de las perspectivas ${ }^{117}$.

El juicio de necesidad está condenado a cierta irracionalidad puesto que, si ya resulta espinoso determinar la idoneidad de una medida penal, su comparación con otras formas hipotéticas de control social que pueden

\footnotetext{
112 Por todos, De la Mata Barranco (2007) 157.

113 De este examen se excluyen aquellas medidas que no pueda implementarse por imposibilidad técnica o por conllevar costes exorbitantes.

114 Un ejemplo paradigmático en nuestra jurisprudencia constitucional sobre las mayores posibilidades de realizar el juicio de necesidad, constituye las prevenciones de los magistrados Bertelsen y Correa Sutil de la STC de 17 de marzo de 2009, Rol No 1145, razonamientos decimosexto a decimonoveno.

115 LASCURAín (1998) 167.

116 STC de España 55/1996, de 28 de marzo.

117 Bernal Pulido (2005) 748.
} 
responder a otras finalidades, este examen puede convertirse en desiderátum inalcanzable ${ }^{118}$. Esta situación se agrava cuando se incluyen los efectos latentes de las normas sometidas a comparación. La inexistencia de datos empíricos suficientes acerca de la incidencia social de las medidas alternativas hace imposible situar el canon de comparación para el juicio de necesidad en una medida hipotética que cumpla exactamente la misma finalidad, el mismo nivel de satisfacción y con menos costes derivados del propio carácter limitador del precepto ${ }^{119}$.

A mi entender, el juicio de necesidad debe realizarse, principalmente, desde un análisis comparativo de la coherencia del legislador y no desde una eventual comprobación empírica sobre el medio más eficaz para alcanzar la finalidad perseguida por la norma, es decir, atendiendo al conjunto de delitos y penas que el legislador ha estimado, previamente, como necesarias para alcanzar fines análogos ${ }^{120}$. Así, se entenderá como desproporcionado -desde una perspectiva externa- cuando concurra un desequilibrio patente o irracional entre la sanción y la finalidad de la norma a partir de su concreción en la propia actividad legislativa. En otras palabras, aceptando como necesarias las medidas penales existentes, el control de una medida con una similar finalidad, estructura típica y, en especial, teniendo presente una previa jerarquización de la lesión o puesta en peligro del bien jurídico a otras medidas penales, entonces existe un parámetro jurídico para establecer su necesidad. Así por ejemplo, la penalidad del delito de homicidio simple se presupone como necesaria a los efectos de protección y prevención del bien jurídico protegido vida, entonces la misma penalidad impuesta, por ejemplo, a los tipos imperfectos de robo con violencia a través del art. $450 \mathrm{CP}$, conlleva a una falta de coherencia sobre la necesidad del aumento de penalidad. La cuestión, de nuevo, es determinar cuándo se entiende irracional o extremadamente desmedida.

\section{(3.1.5) Proporcionalidad en sentido estricto: la ponderación}

Estamos ante el genuino juicio de proporcionalidad, cuya formulación más frecuente es la siguiente: el medio debe encontrarse en una relación justa o razonable con el fin que se aspira ${ }^{121}$. La ponderación presupone un enfrentamiento de dos posiciones jurídicas protegidas por sendos derechos fundamentales y, por tanto, resulta necesario encontrar una solución específica para cada caso concreto. Esta conflicto excluye la

\footnotetext{
118 En el mismo sentido, Lascuraín (1998) 167.

119 LAscuraín (1998) 168.

120 La jurisprudencia del TC español ha establecido, junto a los datos empíricos incuestionados, "el conjunto de sanciones que el legislador ha estimado necesarias para alcanzar fines de protección análogos”. SsTC 55/1996, f.j.8; 161/1997, f.j. 12.

121 Kluth (1998) 228. El autor toma como referencia la jurisprudencia del TC alemán.
} 
defensa de una prioridad abstracta de los derechos fundamentales y analiza la aplicación de reglas de decisión general como el principio in dubio pro libertate, puesto que la ponderación debe resolverse atendiendo al caso concreto. En el mismo sentido, tampoco cabría acudir al principio in dubio pro legislatoris.

La única regla que puede ayudarnos en este conflicto es el denominado "principio de la concordancia práctica”, según el cual la decisión adoptada nunca debe dejar sin contenido a los diferentes valores enfrentados o, desde una perspectiva más ambiciosa, se aspira a que la ponderación permita a los derechos fundamentales enfrentados preservar su contenido en la mayor medida posible ${ }^{122}$.

A diferencia de lo que sucede con los juicios de idoneidad y necesidad, donde el fin perseguido por la intervención pública solo constituía un presupuesto, en el análisis del juicio de ponderación, el objetivo perseguido constituye un elemento esencial del mismo. En este momento la relevancia del fin perseguido se pondera con la relevancia del perjuicio causado a la libertad, por lo que resulta fundamental determinar la importancia de la Constitución concede a la consecución de dicho fin ${ }^{123}$. La doctrina entiende que nos encontramos ante un examen interno, es decir, entre los costes y beneficios de la medida en términos de libertad. Se ha manifestado que su fundamento se encuentra en el terreno de los valores, de la justicia, es decir, si el beneficio que se pretende alcanzar justifica sus costes, mientras que los juicios de idoneidad y necesidad se fundamentan en una racionalidad utilitarista. El juicio de ponderación no compara alternativas, sino solo la medida objeto de control y su finalidad ${ }^{124}$.

El carácter empírico de los juicios de idoneidad y necesidad lleva consigo, como hemos manifestado con anterioridad, que tenga poca relevancia práctica en el test constitucional de proporcionalidad, hecho que ha sido confirmado por la jurisprudencia constitucional comparada. Por esta razón, el juicio de ponderación constituye el aspecto central en el control constitucional de las leyes penales ${ }^{125}$.

La doctrina penal tradicionalmente cuando analiza el principio de proporcionalidad suele referirse a su concepción estricta ${ }^{126}$. Sin embargo, y a pesar de esta restricción, el principio de proporcionalidad en sentido estricto no está exento de una intensa polémica doctrinal que afecta incluso a su justificación como principio penal o límite al ius puniendi ${ }^{127}$.

\footnotetext{
122 Hesse, Konrad (1995). Grundzüge des Verfassungsrecths der Bundesrepublik Deutschland, 20a ed., Heidelberg: C.F. Müller Juristischer, p. 27.

123 KLUTH (1998) 229.

124 González Beilfuss, Markus (2002). El principio de proporcionalidad en la Jurisprudencia del Tribunal Constitucional, Pamplona: Aranzadi, pp. 120 y 171.

125 En el mismo sentido, KLUTH (1998) 232.

126 Véase a Aguado Correa (1999) 147.

127 Así, tras el inicial rechazo de la retribución como fin de la pena -donde inicialmente en-
} 
Pero el principal obstáculo con que topa el principio de proporcionalidad fue puesto ya de manifiesto por Bentham: "la idea fundamental de proporcionalidad de la pena en relación con el delito no ofrece, por sí misma, ningún criterio objetivo de ponderación"128. Ahora bien, la dificultad que entraña la aplicación de este principio no obsta para que tengamos presente varias consideraciones. En primer lugar, el Estado constitucional obliga a priori a un juicio de proporcionalidad respecto de la injerencia en los derechos fundamentales ocasionada tanto por la descripción del injusto como por imposición de la pena. Ferrajoli ha puesto de manifiesto que la falta de atención por parte de la doctrina penal en cuanto a la determinación legislativa tanto de la calidad y cantidad de la pena confirma su actitud acrítica y contemplativa en relación al derecho vigente $^{129}$, situación extrapolable a nuestro TC, que se ha limitado a recordar la potestad exclusiva del legislador para realizar el juicio de proporcionalidad en sentido estricto, afirmación que resulta paradójica con los fundamentos del Estado constitucional, más si tenemos presente el carácter especialmente aflictivo de las penas. Y en segundo lugar, si bien es especialmente complejo medir de manera interna la gravedad de la pena en relación con el injusto, resulta posible y necesario ponderarla respecto del resto de las figuras delictivas, ponderación que no debe realizarse exclusivamente por el legislador, sino también por el $\mathrm{TC}^{130}$.

El juicio de proporcionalidad en sentido estricto o de ponderación puede operar en el ámbito penal en dos momentos diferentes. En primer lugar, respecto a la restricción de libertad que supone el injusto culpa-

cuentra el principio de proporcionalidad su justificación- se ha intentado encuadrarlo dentro de los fines preventivos de la pena, justificación que tampoco ha estado exenta de críticas. Sirva como ejemplo el incremento de penas en ciertos delitos de bagatela, donde la tensión entre las necesidades preventivas y la proporcionalidad resulta inicialmente irresoluble. También su ubicación constituye uno de los aspectos más discutidos: existen tantas propuestas sobre la ubicación dogmática del principio de proporcionalidad como autores que se han ocupado del mismo. Algunos autores entienden que es una consecuencia del principio de culpabilidad; otros afirman que integraría, junto al carácter de ultima ratio y el carácter fragmentario, el principio de necesidad de intervención; también una importante parte de la doctrina lo considera como una consecuencia del principio de mínima intervención; otro grupos de autores se refieren al principio de proporcionalidad en sentido estricto como un límite independiente; y finalmente, los que sustentan que este principio constituye un subprincipio del principio de proporcionalidad en sentido amplio. Véase, Fernández Rodríguez, María Dolores (1994). "Límites al Ius puniendi", Anuario de Derecho Penal y Ciencias Penales, pp. 87-113.

128 Citado por Ferrajoli (1995) 153.

129 Ferrajoli (1995) 339.

130 La STC de España 55/1996 manifiesta: "En relación con la proporcionalidad de una determinada pena, este Tribunal no puede, para establecerla, tomar como referencia una pena exacta, que aparezca como la única concreción posible de la proporción constitucionalmente exigida, pues la Norma suprema no contiene criterios de los que pueda inferir esa medida; pero tampoco le es posible renunciar a todo control material sobre la pena, ya que el ámbito de la legislación penal no es un ámbito constitucionalmente exento". 
ble y, por otra, la restricción de libertad que supone la aplicación de la pena. El juicio de proporcionalidad del injusto punible constituye una restricción a los derechos fundamentales con una finalidad esencialmente preventiva, es decir, destinada a sujetos que no han cometido previamente ningún delito. El contenido y estructura es idéntica a cualquier medida restrictiva de los derechos fundamentales destinada al común de los ciudadanos. En cambio, el juicio de proporcionalidad de la pena, por el contrario, tiene como presupuesto la previa comisión de un delito. De esta diferencia se deriva una importante consecuencia: una mayor legitimidad (racional o no) del legislador para limitar los derechos fundamentales. En el presente estudio solo realizaremos algunas reflexiones sobre la proporcionalidad de la pena.

\section{(3.1.6) El juicio de ponderación en la descripción y determinación de la pena}

Parece evidente que el primer criterio que debe someterse a la ponderación es la finalidad de la medida penal. Aquí parecen existir dos posiciones: la primera hace referencia al bien jurídico protegido o, en otras palabras, a la mayor o menor gravedad del conflicto social que se pretende intervenir penalmente; la segunda acude a los denominados fines de la pena, en especial, a sus versiones preventivas. Ahora bien, si pretendemos encontrar la finalidad última de una intervención penal esta debe encontrarse en el bien jurídico protegido: los fines de la pena no pueden constituirse en la finalidad del derecho penal, salvo en Estados autoritarios, sino en la medida que sirven a la protección del bien jurídico protegido. Pero también es cierto que aquí es donde se produce una de las principales tensiones en el derecho penal: la proporcionalidad entre la justa retribución y las necesidades preventivas del derecho penal ${ }^{131}$.

Además, la teoría del bien jurídico parece también cumplir un papel esencial en el juicio de ponderación a través de la jerarquización en abstracto de los diferentes bienes jurídicos protegidos penalmente. Si por ejemplo, se coloca a la vida por encima de la propiedad, entonces se convierten en baremos para enjuiciar la proporcionalidad de las intervenciones estatales ${ }^{132}$.

El juicio de ponderación como límite al ius puniendi, en términos penales, no supone otra cosa que la transformación de la retribución como fin de la pena a límite de la prevención, que se constituye en genuino fin de la pena. Como la prevención constituye un fin legítimo constitucionalmente, que normalmente es utilizado para imponer una

\footnotetext{
131 Aguado Correa (1999) 191.

132 Hassemer (2007) 99.
} 
pena superior que merece per se el injusto y la reprochabilidad-salvo, por ejemplo, en la Ley de responsabilidad juvenil, donde el interés superior del nińo, que normalmente se concreta en consideraciones preventivo especiales, justifica una pena menor- la cuestión que se suscita es cuándo ese aumento de pena por consideraciones preventivas resulta constitucionalmente desproporcionada.

De acuerdo con De la Mata Barranco, la correspondencia entre la gravedad de la pena y del hecho como único parámetro en el juicio de ponderación, excluyendo consideraciones preventivas resulta incorrecto. La ponderación entre el hecho cometido y la pena encuentra también su justificación en consideraciones preventivas. La necesidad e idoneidad de una pena reclama que esta deba ser graduada. De hecho, en la práctica cualquier juicio sobre la proporcionalidad de una pena en sede legislativa incorpora consideraciones preventivas, la cuestión es qué papel juega en un eventual juicio de proporcionalidad ${ }^{133}$. Aquí de nuevo las limitaciones del juicio de constitucionalidad vuelven a aparecer: la legitimidad del TC para determinar las funciones preventivas de las penas. Lo contrario, es decir, puede llevar a juicios erróneos, dada la evidente menor capacidad del TC para establecer la capacidad preventiva de una pena. Aquí, además de un juicio negativo, solo cabe acudir, valga la redundancia, a una ponderación comparativa. Ahora bien, la justa retribución solo puede delimitarse a través de su comparación con el propio sistema jurídico y, a lo sumo, con otras legislaciones: un delito de peligro contra la vida desde una perspectiva retributiva no puede conllevar una pena igual o superior que la establecida a un delito de lesión contra el mismo bien jurídico.

A pesar de la problemática que encierra la determinación de los criterios que deben sopesarse en el juicio de ponderación, resulta ineludible establecer un referente a la hora de comparar la gravedad de la pena que la mayoría de los autores vinculan con la gravedad del injusto en su aspecto objetivo y subjetivo y, por supuesto, de la culpabilidad en sentido estricto, reprochabilidad o responsabilidad ${ }^{134}$.

Debe valorarse en este juicio de ponderación, en primer lugar, la gravedad del delito (juicio interno) teniendo como referencia los elementos esenciales del delito. Así, deberá tenerse presente: (1) El desvalor del resultado; si estamos ante un delito de lesión o de peligro, y en este último caso, concreto o abstracto. (2) El desvalor de la acción; principalmente si estamos ante un delito doloso o imprudente. (3) El grado de ejecución y participación del delito. (4) En cuanto al desvalor personal se deberá tener presente, esencialmente en nuestro recurso de inaplicabilidad, debido a su presunta condición de control concreto. Así, y continuando con

133 De la Mata Barranco (2007) 257.

134 Por todos, De la Mata Barranco (2007) 202 - 203. 
los postulados asentados en la teoría jurídica del delito podrá valorarse el grado de inimputabilidad, la conciencia de antijuridicidad y el grado de exigibilidad. Por último, además, de los criterios que nos ofrece la teoría jurídica del delito, deben tenerse presente en el juicio de ponderación otros factores como, por ejemplo, la posibilidad de acceder a alguna pena o medida sustituida o beneficio penitenciario.

En segundo lugar, el juicio constitucional de ponderación necesita de un juicio externo con el resto del sistema jurídico e, incluso, con otros sistemas comparados. Es más, el juicio interno de ponderación resulta insuficiente per se si el examen no se compara con otros figuras penales. Este examen interno referido a la estructura interna del delito sirve como presupuesto para el verdadero juicio de ponderación. Así, el establecimiento del delito de tráfico de drogas como un delito de peligro respecto del bien jurídico vida o integridad física, nos aporta el parámetro de proporcionalidad para compararlo con otras figuras penales relacionadas con este, como por ejemplo, con los delitos de lesión de estos bienes jurídico protegidos.

Esta manera de entender el juicio de proporcionalidad podemos encontrar un referente en el denominado test Helm seguido por la CS estadounidense en los años $80^{135}$. El test Helm, teniendo presente que si bien la concreción de la proporcionalidad constituye una competencia legislativa, bajo la Octava Enmienda, estableció que el juicio de constitucionalidad sobre la proporcionalidad de las penas debe guiarse por tres parámetros: una comparación de la gravedad del delito y la severidad de la pena; una comparación de las penas impuestas en la misma jurisdicción por otros crímenes; y una comparación de sentencias impuestas en otras jurisdicciones (Helms, 1983: 291-292)136.

135 La Corte Suprema en Solem v. Helm (463 U.S. 277 (1983), por una mayoría de 5 a 4 invirtió una sentencia de prisión perpetua. Este fallo volvió a retomar el originario caso de Weenms (1910).

136 Citado por Zeigler, Frank A. / Del Carmen, Rolando V. (1996). "Constitutional Issues Arising from "Three strikes and you're out" legislation”, en Shichor, David / Sechrest, Dale (Coords.): Three strikes and you're out. Vengeance as public policy, Thousand Oaks: Sage Publications, pp.12 y ss. A principios de los años 90 la guerra contra las drogas influyó en un cambio jurisprudencial de manera opuesta a la desarrollada en Helm. Este caso abordó la aplicación de una regla de mínima penalidad: la posesión de drogas de más 672 gramos de cocaína obligaba a imponer en el Estado de Michigan una pena de prisión perpetua sin posibilidad de libertad condicional. El juez Scalia volvió a circunscribir la aplicación de la Octava Enmienda a la pena de muerte y propuso anular el precedente de Helm (1983). La sentencia para establecer la gravedad de la conducta acudió a tres efectos del tráfico y consumo de drogas: a) el consumidor de drogas puede cometer delitos porque estas inducen a cambios en su habilidad cognitiva; b) un consumidor de drogas puede cometer delitos para comprar drogas; c) y un crimen violento puede ser debido en parte por la cultura de la droga (Harmelin, 1992: 1002). Zeigler / Del Carmen ponen en evidencia que Harmerlin representa un sutil cambio en el balance entre gravedad del crimen y severidad de la pena. Al conceder los efectos del tráfico de droga en la nación, la CS, en vez de tomar en cuenta 
Véase que los dos últimos establecen una comparación con el propio sistema jurídico penal, es decir, con los diferentes delitos en atención a la lesión o puesta en peligro de los diferentes bienes jurídicos protegidos. El segundo juicio compara la pena con las impuestas en las diferentes jurisdicciones penales federales. En nuestro caso esta comparación podría realizarse con aquellos sistemas jurídicos especialmente relacionados con nuestro sistema jurídico-penal.

La dogmática de los derechos fundamentales ha establecido su propio juicio de ponderación que puede complementarse con los criterios anteriormente expuestos y, de hecho, muchos de los criterios coinciden con alguno de ellos. Aquí solo me detendré en aquellas reglas de ponderación -formuladas por Bernal Pulido- que pueden tener una implicación más directa en el juicio de ponderación de las penas. Tomaremos como referencia la regla de penalidad del art. 450 inc. $1^{\circ} \mathrm{CP}$, precepto que ha sido objeto de un intenso debate doctrinal y jurisprudencial sobre su constitucionalidad.

En primer lugar, cuando sea mayor la importancia de un principio en abstracto dentro del sistema constitucional, mayor será el peso de la ponderación. En este caso, debemos diferenciar entre las diversas figuras enumeradas en el art. 450 inc. $1^{\circ} \mathrm{CP}$, aquellas que protegen esencialmente la propiedad y que, consecuentemente, deberán tener un mayor peso frente a la injerencia de la pena de privación de libertad que establece este precepto.

En segundo lugar, cuando más intensa sea la injerencia en el derecho fundamental, mayor será el peso en la ponderación. Así por ejemplo, en el delito de robo con fuerza en las cosas en casa habitada, el tipo frustrado puede conllevar un aumento de penalidad de cinco ańos de prisión -siempre y cuando sea posible la frustración en los delitos contra la propiedad-.

En tercer lugar, y en sentido contrario, cuando mayor sea la afección de los fines político criminales establecidos por el legislador, mayor peso tendrá en el juicio de ponderación. Aquí, debemos tener presente que, declarada su inconstitucionalidad, estos delitos volverían al redil del sistema general de incriminación del art. 7 CP y, por tanto, no supondría eliminación o merma significativa de las necesidades preventivas del Estado chileno en el control de los delitos contra la propiedad.

los aspectos concretos del supuesto de hecho y, en especial, las características del acusado, se centró en el gravísimo problema social de la droga en la salud y bienestar de la población. Con la justificación de la guerra contra las drogas la CS despojó del gran potencial que tiene la Octava Enmienda para prohibir cadenas perpetuas por un solo delito y por delincuentes reincidentes. Bajo la regla de la teoría del precedente que la última decisión es la mejor decisión, solo en casos excepcionalmente raros se pueden traspasar el umbral puesto por Harmelin. Este precedente ha sido citado por las cortes federales y juzgados de circuito como caso dispositivo de la Octava Enmienda. 
En quinto lugar, cuando más eficaz, probable y rápida sea el fin del legislador (prevenir los delitos contra la propiedad), mayor peso tendrá en el juicio de ponderación. Aquí, ameritaría un estudio sobre la evolución de la delincuencia patrimonial desde la incorporación de este precepto, pero a priori parece que las conclusiones no resultan muy alentadoras.

Por último, cuando mayor sea la afección al contenido esencial del derecho fundamental, es decir, si la posición iusfundamental afectada por la intervención resulta necesaria para que el derecho sea reconocible como tal, esta consideración en el juicio de ponderación debe considerarse muy intensa. En este caso, la pena privativa de libertad supone una afección al derecho fundamental de tal intensidad que apenas hace reconocible el derecho fundamental a la libertad. Relacionado con lo anterior, cuando mayor conexión con la dignidad humana, mayor será su peso en la ponderación ${ }^{137}$.

\section{4) JUICIO CONSTITUCIONAL DE PROPORCIONALIDAD Y LEGITIMA- CIÓN DISCURSIVA}

El juicio de proporcionalidad establece como inconstitucional toda injerencia en los derechos fundamentales que resulte manifiestamente desproporcionada. Esta alusión a los términos, "intolerable", "grave", "desmedidamente desproporcionada", etc., que se establecen como cláusula de cierre de todos los juicios o subprincipios, parece que, en última instancia, queda a juicio del propio TC su concreción.

Esta decisión final puede racionalizarse a través del precedente. Pero a mi entender, no resulta suficiente, por el simple hecho que requiere con carácter previo la adopción de una serie de resoluciones básicas sobre las que construir un desarrollado sistema de precedentes en la jurisprudencia constitucional. Además, si aceptamos como una finalidad del Estado y, por tanto, del TC, reducir o limitar el poder punitivo, esto significa la adopción de nuevos espacios de libertad que superen los límites impuestos por los propios precedentes.

El juicio de proporcionalidad tiene como uno de sus principales méritos o críticas el haber incorporado consideraciones de legitimación social, especialmente, a través de los juicios de idoneidad y necesidad. Quizá, sea el momento de plantearnos la incorporación de criterios de legitimación democrática en las decisiones del Tribunal Constitucional. De hecho, el juicio constitucional de proporcionalidad está lleno de alusiones a referencias a la legitimidad discursiva. Así, en el juicio de ponderación se reconoce que este se encuentra sujeto a la tradición y la

137 Por todos, Bernal Pulido (2005) 74. 
moral cambiante de la sociedad en la que se desarrolle la práctica constitucional ${ }^{138}$.

La inherente imprecisión a la que se ve condenado el juicio constitucional de proporcionalidad hace que este posea un alto componente valorativo que se realiza sobre una endeble base empírica y, por tanto, susceptible de un alto margen de error. Esta situación ha llevado a críticas tales como que este juicio de constitucionalidad no constituye más que un argumento formal y ausente de contenido; un tópico ininteligible, que gracias a su fuerza persuasiva ostenta una gran capacidad de enmascarar valoraciones subjetivas e irracionales de los miembros del $\mathrm{TC}^{139}$. Ahora bien, el juicio constitucional de proporcionalidad, a pesar de estas intensas críticas, si está en condiciones para determinar cuándo una medida penal resulta desproporcionada tanto desde la perspectiva de la idoneidad y la necesidad como de la proporcionalidad en sentido estricto. Por el contrario, a mi entender, su incapacidad se muestra a la hora de decidir cuándo una medida resulta manifiesta o intolerablemente desproporcionada. Recordemos que tanto los defensores del principio de proporcionalidad en sentido amplio y la jurisprudencia constitucional que lo ha venido aplicando, reconocen a este juicio de constitucionalidad una cierta base de irracionalidad. Y es en este punto donde juega un papel fundamental la legitimación democrática, y en especial la discursiva, de las medidas penales. Esta decisión posee una clara naturaleza discursiva ${ }^{140}$. La determinación de lo intolerable depende en gran medida del discurso político criminal imperante en el contexto histórico. A mi entender, esta fuerza persuasiva no debe verse solo como un aspecto negativo, es decir, como una ausencia de justificación, sino también desde la valoración positiva que comprende la integración sociojurídica que subyace de todo discurso.

La cuestión, por tanto, es si resulta legítimo incluir consideraciones discursivas en el test de constitucionalidad y, en caso afirmativo, qué

138 Por ejemplo, en el juicio de idoneidad requiere examinar, junto con los conocimientos científicos, las convicciones sociales en la época de la dictación de la ley. Por todos, Bernal Pulido (2005) 729 - 776. Las sentencias TC de España 55/1996 (f.j.6) y 161/1997 (f.j. 9) incluyen en el juicio de proporcionalidad entre el delito y la pena "las percepciones sociales relativas a la adecuación entre delito y pena”.

139 Calvo González entiende que el juicio de proporcionalidad solo cumple una función narrativa: el juez constitucional toma la decisión conforme a su sana crítica y conciencia y, posteriormente, justifica con los términos de proporcionalidad, racionalidad, arbitrariedad, etc. Calvo González (1994) 33 - 43.

140 Un interesante estudio de la jurisprudencia de la Corte Suprema estadounidense da cuenta de la importancia del cambio del discurso jurídico como antesala de un futuro giro del control constitucional de las leyes penales, tras un periodo de más de 30 años de una política criminal conservadora. Bilionis, Louis D. (2006). "Criminal Justice After the Conservative Reformation”, Georgetown Law Journals. Disponible en: http://findarticles.com/p/articles/ mi_qa3805/is_200606/ai_n16618972/?tag=content;col1 
criterios de racionalización pueden establecerse. La legitimidad de su inclusión proviene de la propia tensión que se produce entre democracia y derechos fundamentales, es decir, en la especial atención que debe tener el TC de no invadir competencias atribuidas al legislador, depositario de la soberanía popular.

Varias son las medidas que podrían adoptarse y que solo enunciaremos sucintamente, sin perjuicio de la necesidad de un ulterior desarrollo y discusión por parte de la dogmática penal, sino también de la constitucional y procesal constitucional y de la teoría del derecho. La primera, radica en articular unos adecuados presupuestos comunicativos, por ejemplo, una conformación pluralista, desde una perspectiva en la composición de los magistrados y asesores, es decir, en términos habermasianos, una comunidad ideal de diálogo. La segunda, abordaría la racionalización de los discursos que inciden en las decisiones del TC: la opinión pública y el discurso de los expertos. Dentro de los segundos, resulta esencial un estudio por parte del TC de la doctrina más autorizada ${ }^{141}$ y el grado de unanimidad de la propia doctrina sobre la cuestión sometida al juicio de constitucionalidad. Respecto de la inclusión de valoraciones sustentadas en la opinión pública, es donde se plantean mayores problemas de legitimidad, puesto que, precisamente, una de las funciones de las constituciones democráticas es la protección de las minorías. En todo caso, la opinión pública incide de manera latente en las decisiones de los tribunales constitucionales $^{142}$. Tampoco podemos desconocer que su incorporación excepcionalmente justificaría una limitación al ius puniendi, sino todo lo contrario, legitimaría una mayor presión penal. En todo caso, debemos de recalcar que estas reflexiones deben tomarse en consideración en los denominados casos difíciles y como último criterio después de los juicios exigidos por el juicio de proporcionalidad. En otras palabras, nuestro TC debe evitar esta tentación de acudir como primer o único parámetro de control las valoraciones de la opinión pública. A lo anterior debemos añadir que la determinación de los derechos fundamentales, al igual que

141 En este aspecto, nuestra jurisprudencia constitucional tiene un largo camino por avanzar. En materia penal, resulta frecuente acudir exclusivamente a manuales generales e, incluso, solo a uno de ellos. También, resultan frecuente citas expresas excesivamente extensas que no guardan relación directa con el objeto del control de constitucionalidad. Incluso, acuden a varios autores para justificar una decisión, cuando estos se encuentran en posiciones totalmente opuestas. Véase, a modo de ejemplo, las SsTC de 6-3-2008, Rol. 825-07-INA y 19-5-2009, Rol 1191-2008-INA.

142 Incluso, en el derecho comparado podemos encontrar ejemplos donde la opinión pública ha sido mencionada expresamente como fundamento de un control constitucional de una ley penal. A modo de ejemplo, podemos traer a colación el primer test constitucional de la mencionada regla de penalidad Three Strikes and You're Out, donde la Corte Federal de California manifestó expresamente como uno de los hechos valorados en la sentencia el referéndum realizado en 1994 (Proposition 184), aprobado con un $72 \%$ de aquiescencia a favor de esta regla de penalidad. People v. Romero, California, Rptr. 2d, 1995. 
el proceso de legitimación de las leyes, posee una dimensión discursiva, no solo porque su contenido deba establecerse a través de una comunidad ideal de diálogo, sino también porque es fruto de las presiones discursivas de los más poderosos, presión que suele incidir en su impunidad.

Sin perjuicio de si resulta legítimo o no la inclusión de este tipo de consideraciones discursivas en este test de constitucionalidad, su inclusión supondría considerar variables empíricas como, por ejemplo, las encuestas de opinión.

Para terminar, la última y más importante medida de racionalización fundamentada en consideraciones democráticas consiste en establecer la cláusula de cierre en el control de constitucionalidad de las leyes más allá de los propios tribunales constitucionales.

La tensión entre derechos fundamentales y democracia resulta irresoluble, es más, constituye una característica saludable de todo Estado constitucional. Cuando nos encontramos ante este tipo de tensión normativa y política solo cabe racionalizarla a través de la inclusión de nuevos factores procedimentales que permitan un juicio más sosegado y racional. Sin duda, la inclusión del TC en los Estados a partir de la segunda mitad del siglo XX supuso la inclusión de un nuevo actor y de nuevo un procedimiento que posibilitó juicios más racionales en la elaboración de las leyes. Por tanto, la inclusión de los tribunales constitucionales de este nuevo actor fue circunstancial e histórica y quizá debamos plantearnos la inclusión de un nuevo actor en el proceso de racionalización de las leyes. Si efectivamente la Constitución supone la manifestación del poder constituyente, resultaría sugerente que la cláusula de cierre se circunscribiera en este último poder. Como manifiesta Habermas, "es digna de tenerse en cuenta de si la revisión de tal decisión parlamentaria no podría efectuarse a su vez en forma de autocontrol mismo del legislador, organizando tal control a modo de tribunal, e institucionalizándolo, por ejemplo, en una comisión parlamentaria compuesta también por profesionales del derecho" 143 .

Esta última propuesta relativa a la supresión de los tribunales constitucionales tiene dos inconvenientes. El primero, al suprimirse el TC se atentaría contra el propio principio discursivo, al eliminar a un participante racional inserto en la cultura jurídica. Y el segundo, el control parlamentario se puede convertir en la práctica en un mero trámite sometido a la disciplina de los partidos políticos. A mi parecer, lo correcto sería mantener el TC y en casos excepcionales que el Parlamento, previo a una serie de requisitos procedimentales, se constituya en el último intérprete de la Constitución. Es más, se podrían requerir las mismas exigencias necesarias para una reforma constitucional, por ejemplo, un quórum cua-

143 Habermas, Jürgen (1998). Facticidad y validez. Sobre el derecho y el Estado democrático de derecho en términos de teoría del discurso, trad. de Jiménez Redondo, Madrid: Trotta, p. 314. 
lificado tanto para presentar el recurso contra la resolución del TC ante el Parlamento como para resolverlo. Esta propuesta, además de favorecer los procesos discursivos en el control constitucional de las leyes, eliminaría parte de la tensión a la que se ven abocados los tribunales constitucionales en la actualidad. También esta propuesta no afectaría, al menos sustancialmente, a su función indispensable para el mantenimiento de la propia democracia: en otorgar un catálogo de derechos y principios a las minorías para defenderse de los abusos que pudiera cometer la mayoría y con ello garantizar la limpieza del juego democrático ${ }^{144}$.

Sin duda, esta propuesta no estará exenta de manipulaciones por parte de los grupos parlamentarios, manipulación que, en todo caso, se encuentra también expuesto el TC. Por tanto, este nuevo actor y procedimiento encontraría su ámbito de aplicación en los casos difíciles que dividen a una determinada sociedad, la sentencia de la pildora del día después, constituye un ejemplo paradigmático de esta situación.

El TC no puede adoptar el papel de un regente que ocupa el lugar del sucesor en el trono ante la minoría de edad de la sociedad y de sus representantes políticos. A los sumo, en una comunidad de ciudadanos formados en la cultura constitucional solo puede adoptar el papel de tutor ${ }^{145}$.

\section{BIBLIOGRAFÍA}

- Aguado Correa, Teresa (1999). El principio de proporcionalidad en derecho penal, Madrid: Edersa.

- Alexy, Robert (2007). Teoría de los derechos fundamentales, 2a ed., trad. de Bernal Pulido, Madrid: Centro de Estudios Constitucionales.

- Aristóteles. Obras completas. Ética a Nicómano. Disponible en http://www.uruguaypiensa.org.uy/imgnoticias/650.pdf [Fecha de visita 11 de febrero de 2010].

- Asúa Batarrita, Adela (1990). "Reivindicación o superación del programa de Beccaria”, en ella misma: El pensamiento penal de Beccaria: su actualidad, Bilbao: Universidad de Deusto.

- Barnes VÁsquez, Javier (1998). "Principio de proporcionalidad en el derecho comparado y comunitario”, Cuadernos de Derecho Público, No 5.

- Bascuñan Rodríguez, Antonio (2004). "Delitos contra intereses instrumentales", Revista de Derecho, No 1, Universidad Adolfo Ibáñez, pp. 323 y ss.

- Bernal Pulido, Carlos (2005). El principio de proporcionalidad y derechos fundamentales, Madrid: Centro de Estudios Constitucionales.

\footnotetext{
144 Laporta, Francisco (2002). "El ámbito de la Constitución”, Doxa, No 24, pp. 460 y ss.

145 Habermas (1998) 354.
} 
- Bilionis, Louis D. (2006). "Criminal Justice After the Conservative Reformation”, Georgetown Law Journal. Disponible en: http://findarticles.com/p/articles/mi_qa3805/is_200606/ai_ n16618972/?tag=content;col1

- Böse, Martin (2007). "Derechos fundamentales y Derecho penal como "derecho coactivo"”, en Hefendehl, Roland (ed.): La teoría del bien jurídico. ¿Fundamento de legitimación del derecho penal o juego de abalorios dogmático?", Madrid: Marcial Pons.

- Bunzel, Michael (2007). "La fuerza del principio constitucional de proporcionalidad como límite de la protección de bienes jurídicos en la sociedad de la información”, en Hefendehl, Roland (ed.): La teoría del bien jurídico. ¿Fundamento de legitimación del derecho penal o juego de abalorios dogmático?", Madrid: Marcial Pons.

- Calvo GonzÁlez, José (1994). "Razonabilidad como relato (Narrativismo en la observancia y divergencia del precedente)", Revista del Poder Judicial, No 33, pp. 33-43.

- Cuerda Arnau, María Luisa (1997). "Aproximación al principio de proporcionalidad en derecho penal", en VV. AA: Estudios jurídicos en memoria del profesor Dr. José Ramón Casabú Ruiz, Valencia: Universitat-Instituto de Criminología, pp. 496 y ss.

- De la Mata Barranco, Norberto J (2007). El principio de proporcionalidad penal, Valencia: Tirant lo Blanch.

- De Otto y Pardo, Ignacio (1983). "La regulación del ejercicio de los derechos y libertades. La garantía de su contenido esencial en el artículo 53.1 de la Constitución”, en Martín-Retortillo / De Otto y Pardo (Coords.): Derechos fundamentales y Constitución, Madrid: Cuadernos Civitas Derecho Constitucional, pp.115 a 119.

- Díez Ripollés, José Luis (2005). "El control de constitucionalidad de las leyes penales", en Revista Española de Derecho Constitucional, No 75 .

- (2003). Racionalidad de las leyes, Madrid: Trotta.

- Dworkin, Ronald (1984). Los derechos en serio, Barcelona: Ariel.

- Ferrajoli, Luigi (1995). Teoría del garantismo penal, Derecho y razón, Madrid: Trotta.

- Fernández Cruz, José Ángel (2009). "La legitimidad social de las leyes penales: límites y ámbito de aplicación”, Revista de Derecho de la Pontificia Universidad Católica de Valparaiso, vol. XXXIII, pp. 232-259.

- Fernández Rodríguez, María Dolores (1994). "Límites al Ius puniendi", Anuario de Derecho Penal y Ciencias Penales.

- Fuentes Cubillos, Hernán (2008). "El principio de proporcionalidad en derecho penal. Algunas consideraciones acerca de su concretización en el ámbito de la individualización de la pena", Ius et Praxis, vol. $14, \mathrm{No} 2$. 
- Gómez Benítez, José Manuel (2001). “La idea moderna de la proporcionalidad de las penas", Estudios Penales.

- Gómez Recio, Fernando (2000). "El principio de proporcionalidad penal, doctrina constitucional y su aplicación a los delitos de tráfico de drogas", Actualidad Penal, No 45.

- González Beilfuss, Markus (2002). El principio de proporcionalidad en la Jurisprudencia del Tribunal Constitucional, Pamplona: Aranzadi.

- Habermas, Jürgen (1998). Facticidad y validez. Sobre el derecho y el Estado democrático de derecho en términos de teoría del discurso, trad. de Jiménez Redondo, Madrid: Trotta.

- Hassemer, Winfried (1989). "Lineamientos de una teoría personal del bien jurídico", DP, No 46, pp. 275-285.

(2007). "¿Puede haber delitos que no afecten a un bien jurídico penal?”, en Hefendehl, Roland (ed.): La teoría del bien juridico. ¿Fundamento de legitimación del derecho penal o juego de abalorios dogmático?, Madrid: Marcial Pons.

- Hesse, Konrad (1995). Grundzüge des Verfassungsrecths der Bundesrepublik Deutschland, 20a ed., Heidelberg: C.F. Müller Juristischer.

- Hormazábal, Hernán (1991). Bien juridico y Estado Social y Democrático de Derecho, Barcelona: P.P.U.

- JaÉn Vallejo, Manuel (1999). Los principios superiores del Derecho Penal, Madrid: Dykinson.

- Jiménez Campos, J. (1999). Derechos fundamentales. Concepto y garantías, Madrid: Trotta.

- Kluth, Winfried (1998). "Prohibición de exceso y principio de proporcionalidad en el derecho penal alemán”, Cuadernos de Derecho Público, No 5.

- Künsemüller, Carlos (2001). Culpabilidad y pena, Santiago: Editorial Jurídica de Chile.

- Lagodny, Otto (2007). "El derecho penal sustantivo como piedra de toque de la dogmática constitucional”, trad. de Ínigo Ortiz de Urbina Jimeno, en Hefendehl, Roland: La teoría del bien jurídico. ¿Fundamento de legitimación del derecho penal o juego de abalorios dogmático?", Madrid: Marcial Pons.

- Laporta, Francisco (2002). "El ámbito de la Constitución”, Doxa, No 24, pp. 460 y ss.

- Lascuraín Sánchez, Juan Antonio (1998). "El principio de proporcionalidad penal", Cuadernos de Derecho Público, No 5.

- Lepsius, Oliver (2001). "Das verhältnis von Sicherheit und Freiheitsrechten in der Bundesrepublik Deutschland nach dem 11. September 2001". Disponible en http://aicgs.org/documents/lepsius. pdf, p.16 [Fecha de visita: 15 de abril de 2010].

- Lopera Mesa, Gloria P. (2006). Principio de proporcionalidad y ley penal, Madrid: Centro de Estudios Políticos y Constitucionales. 
- Mayer, Otto (1940). Derecho administrativo alemán, Buenos Aires: De Palma.

- Mir Puig, Santiago (2002). Derecho penal. Parte General, 6a ed., Barcelona: Reppertor.

- Nogueira Alcalá, Humberto (2010). "El principio de proporcionalidad y su aplicación en Sudamérica por la jurisdicción constitucional, con especial mención al tribunal constitucional chileno" en Carbonell, Miguel (coord.): El principio de proporcionalidad en la interpretación jurídica, Santiago: Librotecnia, pp. 400 y ss.

- Oliver Calderón, Guillermo (2007). Retroactividad e irretroactividad de las leyes penales, Santiago: Editorial Jurídica de Chile.

- Palazzo Francesco (1998). "Offensività e ragionevolezza nel controllo di costituzionalità sul contenuto delle leggi penali”, RIDPP.

- Parejo, Luciano (1982). "El contenido esencial de los derechos fundamentales en la jurisprudencia constitucional; a propósito de la sentencia del Tribunal Constitucional de 8 de abril de 1981", Revista Española de Derecho Constitucional, No 3.

- Prieto Sanchís, Luis (1997). "La doctrina de los principios generales del Derecho y la distinción entre principios y reglas", en él mismo: Lecciones de teoría del Derecho, Madrid: McGraw-Hill.

- Prieto Sanchís, Luis (2000). "La limitación de los derechos fundamentales y la norma de clausura del sistema de libertades", Revista del Instituto Bartolomé de Las Casas, No 8, pp. 441 y ss.

- Prieto SANChís, Luis (2003). Justicia constitucional y derechos fundamentales, Madrid: Trotta.

- Roxin, Claus (2006). Derecho penal. Fundamentos. La estructura jurídica del delito, trad. de Diego Luzón Peña, Miguel Díaz y García y Javier de Vicente, Madrid: Civitas.

chen: C.H. Beck.

(2006). Strafrecht Allgemeiner Teil, vol. I, 4a ed., Mün-

- SÁnchez García de PAz, Isabel (1994). "El principio constitucional de proporcionalidad en el derecho penal", La Ley, 1994, t. IV.

- Sánchez Martínez, Olga (2004). "Los principios en el Derecho y la dogmática penal", Cuadernos Bartolomé de Las Casas, pp. 70 y ss.

- Schünemann, Bernd (2007). "El principio de proporcionalidad de bienes jurídicos como punto de fuga de los límites constitucionales de los tipos penales y de su interpretación”, en Hefendehl, Roland (ed.): La Teoría del bien jurídico. ¿Fundamento de legitimación penal o juego de abalorios dogmáticos?, Madrid: Marcial Pons.

- Serrano Maíllo, Alfonso (2009). Introducción a la Criminología, 6a ed., Madrid: Dykinson.

- Silva Sánchez, Jesús María (1997). "Nuevas tendencias político criminales y actividad jurisprudencial del Tribunal Supremo", en Romeo Casabona, Carlos (ed.): Dogmática penal, Politica criminal y 
criminología en evolución, Tenerife: Universidad de Tenerife, Centro de Estudios Criminológicos.

- Stächelin, Gregor (1999). "Es compatible la "prohibición de infraprotección" con una concepción liberal del derecho penal", trad. de Felip Saborit, en VV. AA: La insostenible situación del derecho penal, Granada: Comares.

- Sternenberg-Liben, Detlev (2007). "Bien jurídico, proporcionalidad y libertad del legislador penal", trad. de Ortiz de Urbina, en Hefendehl, Roland (ed.): La teoría del bien jurídico. ¿Fundamento de legitimación del derecho penal o juego de abalorios dogmático?, Madrid: Marcial Pons, 2007.

- Torío López, Ángel (1986). "La prohibición constitucional de penas y tratos inhumanos o degradantes", Poder Judicial, No 4, pp. 69-82.

- Zagrebelsky, Gustavo (1996). El derecho dúctil: ley, derecho y justicia, Madrid: Trotta.

- Zeigler, Frank A. / Del Carmen, Rolando V. (1996). "Constitutional Issues Arising from "Three strikes and you're out" legislation", en Shichor, David / Sechrest, Dale (Coords.): Three strikes and you're out. Vengeance as public policy, Thousand Oaks: Sage Publications. 